\title{
Gauging the Effectiveness of Sector Rotation Strategies: \\ Evidence from the U.S and Europe
}

\author{
by Constantinos Alexiou and Anshul Tygi
}

\begin{abstract}
This paper examines the performance of different sector rotation strategies for the U.S. and European market spanning the period 1999 to 2019. By utilising three different strategies we shed further light on the effectiveness of interest rate, momentum, \& FamaFrench 3 and 5 factor alphas as switching signals to enter and exit a particular sector. The emerging evidence suggests that within the European market, sector rotation strategies tend to produce returns above the average benchmark, both during contractionary and expansionary monetary policy regimes, whilst excessive returns within both the US and European markets are observed.
\end{abstract}

Keywords: Sector rotation, Fama-French, Momentum, Interest rate, Business cycles JEL Classification: E32; E52; G11 


\section{Inroduction}

Over the last decade, sector rotation - one of the most prevalent and effective dynamic asset allocation strategies - has gained considerable attention from investors. Its rationale is premised on the maintenance of a balance between passive indexing strategies and active stock picking. It assigns asset allocation in accordance with the current stage of business cycle by taking a long stance on sectors which exhibit the potential to perform well in the future and short on sectors expected to perform poorly. In this context, more than a thousand exchange traded funds (ETFs) throughout the world have been constructed to allow investors to limit their exposure to certain sectors, making sector rotation attractive to investors.

In the extant literature two potential reasons are proposed to explain the impact of economic cycles on different sectors; a) the existence of fundamentals, i.e. certain sectors benefit/suffer in relation to other sectors during the boom/bust cycle because of difference in underlying fundamentals (business models) among different sectors; b) the existence of psychological aspects associated with investor sentiments about one sector in comparison to the future performance of other sector.

While a significant number of studies have been conducted on the concept of sector rotation strategies, a common recurring theme amongst them have been the focus on majorly the US market, and the use of investment tools such as mutual funds. The obvious problem with this recurring theme is that the conclusions drawn from such a limited data source and the lack of diversity in factors considered may be subject to various biases. This inherently makes the practical applicability of these conclusions somewhat restricted, regardless of their theoretical premise. 
It has been over a decade since the Great Recession erupted in 2007/8, and Europe is still trying to recover from the shock and derailed many EU economies. The US economy recovered relatively faster and has been close to its pre-crisis levels since 2011 . The difference in the recovery and growth of the equity market in these two regions can to a certain extent be attributed to the existing differences in their regulatory and monetary policies adopted by their respective monetary institutions i.e. the ECB and the Federal Reserve. The underlying different approaches as to how these regions dealt with the global financial crisis in conjunction with the performance of their respective equity markets provided the impetus for this study to explore the differences in the sector rotation strategies hence, enabling us to gain a more insightful understanding.

This paper aims to address these problems and break new ground in the area by offering more robust conclusion. The contribution of the paper is threefold: the first contribution of this paper lies within the range and diversity of data taken into consideration. Unlike the majority of the previous studies solely focusing on the U.S. market, this paper also takes into consideration the European market. This will enable us to identify if there exists a 'universal' indicator that can perhaps predict the right timing for switching between sectors within different economies. To the best of our knowledge this is the first study trying to gauge the effectiveness of different sector rotation strategies in the European market. Moreover, the use of the three major indicators collectively in one study is another contribution to the existing literature whilst at the same time we focuses on the use of ETFs as a tool to execute the strategies.

The rest of the paper is organized as follows: section 2 reviews the existing literature whilst section 3 elaborates on the methodological framework utilized. Section 4, presents and discusses the results and finally section 5 provide some concluding remarks. 


\section{Related Literature}

Over the years, several studies have emerged in an attempt to examine the effectiveness of sector rotation strategy. Jacobsen, et al. (2009) argued that investing money on sector rotation was able to generate higher returns in comparison to a passive investment strategy of "buy and hold". Grauer et al (1990) constructed a multi-period investment model with 12 industry indices to create a sector rotation strategy and found out that equally weighted portfolios were able to outperform value-weighted portfolios. In the same spirit, Doeswijk and Vliet (2011) successfully predicted future sector returns using the momentum and season factor, and thereafter created a sector rotation strategy using these factors for a number of countries in which the strategy obtained an average annual return of $12.9 \%$ from 1970 to 2008. In an attempt to predict future returns for various sectors Rapach et al (2015) constructed three econometric models the results of which were used to design three sector rotation strategies. The generated average annual alpha returns from 1985 to 2012 were $7.82 \%$ and $12.28 \%$ respectively. Beller, Kling and Levinson (1998) using key macroeconomic variables found that switching sectors based on mean-variance optimisation was able to outperform the benchmark and generate statistically significant monthly returns of about $1.7 \%$ from 1981 to 1995 .

The majority of the existing literature is concentrated on the mutual fund performance and has paid relatively very little attention to sectoral performance. For instance, Dellva, De Maskey and Smith (2001) studied the performance of the 35 Fidelity sector mutual funds during the 1989-1998 time period. Throughout the sub-periods, the value of Jensen's alpha was observed as positive and within the range of 24 to 33 . The only exception was between the time periods 1994-1998, as in this period the alpha values were in negative. Similarly, Kacperczyk, Sialm and Zheng (2005) studied the relationship 
between industry concentration and the performance of actively managed U.S. mutual funds from 1984 to 1999 . The paper argued that mutual fund managers may benefit more from concentrating their holdings in specific sectors/industries than from a welldiversified portfolio.

In contrast, Dou et al. (2014) studied cross-regional and cross-sectoral asset allocation in both bullish and bearish market and reported net positive alpha for Energy, Technology, and Healthcare sectors; and negative alphas for Durable, Telecom, and Manufacturing sectors. In a study to understand the impact of business cycles on stock returns, Chordia and Shivakumar (2002) found that momentum driven trading strategies were only able to statistically outperform the market during periods of expansion however it failed to perform equally well during periods of recession. In this context, it is argued that if we can predict the current phase of the business cycle, then it would help to predict the sectors capability to outperform or underperform the market (Luk 2012).

\subsection{Macroeconomic considerations}

In the past several studies tried to explore the nature of relationship between macroeconomic variables and sectoral performance in different economies including inter alia a study by Deodola and Lippi (2005) which analysed cross-sectoral effects arising from monetary policy in five OECD countries or Hayo and Uhlenbrock (1999) who estimated cross-sectoral effects in Germany. Apart from them most of the previous literature on this aspect of sector rotation has primarily focused on the US market include, Conover, et al. (2005).

Kouzmenko and Nagy (2009) in a study on the association between business cycles and sectoral performance in developed economies namely, U.S., Europe, and Japan found that 
sectors showing high cyclicality were able to outperform sectors which reflected the existence of strong defensive behaviour in the time of expansion and vice versa. Siegel and Hoban (1991) presented an alternative sector rotation strategy where the author switched from equities to bonds based on the stage of the business cycle resulting in excess returns. Ahmed, Lockwood, and Nanda (2002) found that using more than one category of stocks (e.g. mid-cap growth equity) based rotation strategy can enhance the performance of the portfolio much better than by simply rotating across unilateral categories (e.g. mid cap equity).

Building upon their previous work, Conover, et al. (2008) established that cyclical sectors performance is enhanced by easing of monetary policy while that of non-cyclical sectors is enhanced by tight monetary policy. This strategy was able to outperform the benchmark by $3.4 \%$ higher yield.

Jensen and Johnson (1995) studied the daily returns after interest rate changes and found that monetary easing leads to positive abnormal returns for a period of time while monetary tightening leads to negative results. To understand the cross-country and crosssector impact of Federal monetary policy, Ehrmann and Fratzscher (2004) conducted a study and found out that cyclical sectors are relatively more sensitive towards changes in interest rate ranging from a $7.4 \%$ response of the information technology sector to $1.6 \%$ for the utilities sector. In this paper it was established that certain non-cyclical sectors such as food, agriculture and beverages to be least sensitive to changes in interest rate. Bernanke and Kuttner (2005) studied the impact of changes in monetary policy on the equity prices and found out that an unexpected 25 basis point drop in the Federal funds rate can lead to $1 \%$ increase in the broad stock indexes. The paper also argued that cyclical 
sectors respond more sensitively to changes in interest rate, similar to Ehrmann and Fratzscher (2004).

Even though it becomes apparent from the above that using regime changes in the interest rate as an indicator for sector rotation is advantageous a number of limitations have to be considered. Moe specifically, the nature of the relationship between the central banks' monetary policy, business cycles and other macroeconomic conditions is highly convoluted, hence making it hard to understand their causal dimension (see, Durham (2005).

\subsection{Momentum trading strategy considerations}

Past research on the examination of time-series predictability of stock returns on historical basis research established that the predictable patterns in stock returns can be used to outperform the market. However, most of the traditional risk-based asset pricing models have failed to explain the stock returns which led researchers to look for answers in the behavioural theories that could explain the returns and the associated trends. In this context, Jegadeesh and Titman (1993) revealed the presence of positive autocorrelations (momentum) in stock returns in short- and medium-term horizon.

In line with the popular view held by many that individuals tend to overreact to new information, De Bondt and Thaler (1985) found that overreaction caused by new information have significant impact on stock prices. The authors suggested that contrarian strategies achieve abnormal returns due to investors 'overreaction' during periods of poor performance.

Jegadeesh and Titman (1993) found out that strategies focusing on return reversals are transaction intensive $\&$ rely on short term price volatility, therefore making the success 
of the strategy rather questionable and suggesting that these abnormal returns may be because of short-term price pressure or a lack of liquidity in the market rather than overreaction. Levy (1967) stated that a trading strategy based on buying stocks with current prices that are substantially higher than their average prices over the past 27 weeks realizes significant abnormal returns. However, Jensen and Bennington (1970) analysed the same strategy over an extended period of time, mostly outside Levy's sample period and found contradictory results and hence attribute Levy's result to a selection bias.

Sorensen and Burke (1986) studied the relative strength index (RSI) of 43 sectors in US from 1972 to 1982 and found that a sector rotation strategy based on buying and holding the best performing sectors may enhance returns. Similarly, Cavaglia and Moroz (2002) while studying cross-sector and cross-country allocation framework used multi-factors such as price momentum, dividend yield, EPS forecast and found that a strategy focused on investing in profitable, fairly priced, and with positive momentum sectors generated average annualized returns between $3 \%$ and $4.5 \%$ from 1990 to 2001 . Grinblatt and Titman $(1989,1991)$ studied a number of the mutual funds from 1975 to 1984 and found out that a majority of them preferred to buy stocks that showed surge pricing over the previous quarter.

Jegadeesh and Titman (1993) documented that going long on stocks with superior performance in past and going short on stocks with poor performance in the past generated significant positive returns over 3- to 12-month holding periods. Additionally, the authors suggested the reason behind abnormal returns is that the investors buying past winners and selling past losers causes a temporary shift in the prices away from their original pathway values, which results in price overreaction. 
Although the current academic literature has preferred contrarian strategies over relative strength trading strategies, however many practitioners still use relative strength as a criterion for stocks screening. But since the seminal work of Jegadeesh and Titman (1993) many other academicians and practitioners have tried to explore the impact of momentum effect (anomaly) on stock returns. However, unlike the long-term return reversal, all the popular asset pricing models fail to effectively explain the momentum effect, making it an anomaly and is therefore subject to further analysis.

Moskowitz and Grinblatt (1999) argued that most of the momentum-based returns can be captured by forming industry/sector-based portfolios. The authors utilised sector momentum to construct a sector rotation strategy. The strategy used was to use the front 6 month returns to categorize twenty US sectors, and then go long on the three best performing sectors and go short on three worst performing sectors. This strategy obtained an average monthly return of $0.43 \%$ from 1963 to 1995 . Continuing the work of Moskowitz and Grinblatt (1999), O'Neal (2000) suggested the use of tradable assets based on distinct sectors, specifically sector based mutual funds, to generate superior returns arising from the momentum effect. Later, Swinkels and Tjong-A-Tjoe (2008) proposed the use of exchange traded funds for the same purpose.

Scowcroft and Sefton (2005) investigated cross-sector and cross-country based rotation strategies in order to identify if the strategy could be used to outperform the market from 1980 to 2003. By estimating a Linear Factor Model (LFM) based on industry, country and country specific factors to better understand the driving force behind stock momentum the found that $58 \%$ of the momentum is attributed to industry factors and $8 \%$ to stock momentum in case of market value weighted portfolio. However, $66 \%$ is attributed to stock momentum in case of equally weighted portfolio. 


\subsection{Multifactor asset pricing considerations}

Fama and French (1993)'s three-factor model (FF3), Carhart (1997)'s four-factor model and Fama and French (2015)'s five factor model (FF5) are the most commonly used multi factor asset pricing models and performance evaluation tools in empirical research. Despite the popularity of FF3 model, several papers suggested the limitations of FF3 model in explaining many capital market anomalies including the cross-section of stock returns.

Although the FF3 model is an extension of CAPM, by adjusting for outperformance tendencies observed in CAPM, it still failed to account for cross-sectional variation in expected returns primarily associated with investment factor and profitability factor. A number of papers supported this finding, include inter alia Chen et al (2011), Aharoni et al. (2013), and Walkshäusl and Lobe (2014).

Other major anomalies that remains unanswered by FF3 model are positive relationship of average returns with surprises associated with momentum and earnings, negative relationship of average returns with financial hardship, idiosyncratic volatility, net equity issues and growth in assets. These anomalies have been studied in depth by many authors (see for example Spiess and Affleck-Graves, 1995 and Chan, Jegadeesh, and Lakonishok 1996). To counter such limitations, Fama and French (2015) proposed the five-factor model - i.e. extending on previous FF3 model - by further adding two extra factors profitability and investment and found it to be more effective than the FF3 model.

In view of the preceding analysis we procced to the empirical investigation whereby three methodological approaches are used to investigate the three different strategies and shed further light on the effectiveness of interest rate (economic indicator), momentum 
(technical indicator), and Fama-French 3 and 5 factor alphas (performance indicators) as switching signals to enter and exit a particular sector.

\section{Methodological framework}

To investigate the effectiveness of macroeconomic factors i.e. changes in GDP and the interest rate we collate monthly returns of SPDR Sector ETFs for both US and Europe spanning the period January 1999 to June 2019. The main data sources were OECD and the Federal Reserve Bank of St. Louis. The changes were categorised into periods of growth and decline. For the interest rate shifts, the Fed Funds Target rate for the U.S. and Euro Main Refinancing Announcement Rate for European market has been used over the same period. Interest rate changes were categorised into monetary easing or tightening. The main data providers were Bloomberg and DATASTREAM.

For the empirical investigation 9 US sector ETFs and 10 European sector ETFs are considered. The sectors for both the markets have been categorised into either cyclical or non-cyclical sectors based on MSCI's classification criteria on GICS code. Cyclical sectors, by definition, are more sensitive to changes in market and other related macroeconomic variables than non-cyclical sectors.

The monthly returns of the sector-based ETFs for the U.S. and Europe are analysed and compared to the monthly returns of their benchmarks, namely, S\&P 500 Index and Stoxx respectively. To assess the effectiveness of monetary policy as an indicator for sector rotation this paper follows Conover et al., (2008), i.e. an equity portfolio was constructed by investing in an equally weighted portfolio comprising of all the cyclical sector ETFs in periods of monetary easing, and investing in an equally weighted portfolio comprising of all the defensive (non-cyclical) sector ETFs during periods of monetary tightening. In 
passing, it should be noted that transaction costs are assumed to be zero due to the complexities involved in allocating the transaction cost to each transaction as they are based on a number of factors such as tracking error, ETF Bid/Ask spread, commission etc.

We then proceed to assess the second strategy by creating a momentum-based portfolio with some modifications (see Jegadeesh and Titman, 1993). To reflect the price momentum, this section uses previous " $\mathrm{J}$ " month's returns to construct a portfolio and the performance is measured over the next " $\mathrm{K}$ " months. For this section, 16 portfolios were created for each economy with "J" and "K" taking values of 1, 3, 6, and 12 months.

Using 1 month previous returns as " $\mathrm{J}$ " and holding period of 1 month as " $\mathrm{K}$ " are an addition to Jegadeesh and Titman (1993) as some other empirical papers such as Moskowitz and Grinblatt (1999) and Grundy and Martin (2001) found the sector momentum to be strongest at 1 month time interval. The momentum portfolios were created by taking only long positions in the top 3 sectors with highest momentum for each value of "J".

The Winner sectors in this section are ranked based on the work of De Bondt and Thaler (1985) and Jegadeesh and Titman (1993), which define the most commonly used methods at present. The criteria for determination of ranking of the sectors is based on the performance in the formation period. The most common methods of calculating cumulative stock return for a time period are either arithmetic mean or geometric mean. We have adopted the arithmetic mean for calculating cumulative returns of the formation period as Jacquier, Kane and Marcus (2003) reported that for short term investment horizons the arithmetic mean gives results closer to "unbiased compounding rate" and for 
long term horizons the geometric mean minimises bias and presents results closer to "unbiased compounding rate".

The formula for calculating the return is as follows:

$$
\operatorname{Arithmetic~Mean}\left(R_{i, T}\right)=\frac{1}{T} * \sum_{i=1}^{T} \operatorname{Return}(i)
$$

where, Arithmetic Mean $\left(\mathrm{R}_{\mathrm{i}, \mathrm{t}}\right)$ denotes the buy-and-hold return for sector "i $\mathrm{i}$ " within the formation period; Return $\left(\mathrm{R}_{\mathrm{i}}\right)$ is the monthly return of sector " $\mathrm{i}$ " within formation (ranking) period; and $\mathrm{T}$ is the month of sector returns under consideration within formation period.

Sectors are ranked based on the above criteria and the top 3 sectors are included in the winner portfolio on an equally weighted basis. After ranking, the zero-cost sector portfolio tagged as "Winner Portfolio" is bought for K months. The overall return of the winner portfolio here is the equally weighted average of the cumulative return of different stocks that constitute the portfolio within holding period. After $\mathrm{J}$ months, the portfolio is rebalanced using the same steps as mentioned above and the returns are calculated, and the process continues till the end of the sample period.

In table 1 in the appendix a pictorial representation of sector rotation strategy based on previous " $\mathrm{J}$ " months performance and " $\mathrm{K}$ " months investment horizon with $\mathrm{J}=6$ and $\mathrm{K}=3$ is provided.

Finally, in exploring the risk-adjusted performance of the U.S. and European equity sector portfolios we utilize the Fama and French five factor sector rotation strategy based on alpha as a performance indicator and switching signal as a framework, (see, Sarwar, Mateus, and Todorovic, 2017). 
The model specification for the respective asset pricing models are expressed as follows:

1. Fama-French - 3 Factor Model

$\mathrm{R}_{\mathrm{it}}-\mathrm{R}_{\mathrm{ft}}=\alpha_{\mathrm{it}}+\beta_{1}\left(\mathrm{R}_{\mathrm{Mt}}-\mathrm{R}_{\mathrm{ft}}\right)+\beta_{2} \mathrm{SMB}_{\mathrm{t}}+\beta_{3} \mathrm{HML}_{\mathrm{t}}+\varepsilon_{\mathrm{it}}$

2. Fama-French - 5 Factor Model

$\mathrm{R}_{\mathrm{it}}-\mathrm{R}_{\mathrm{ft}}=\alpha_{\mathrm{it}}+\beta_{1}\left(\mathrm{R}_{\mathrm{mt}}-\mathrm{R}_{\mathrm{ft}}\right)+\beta_{2}\left(\mathrm{SMB}_{\mathrm{t}}\right)+\beta_{3}\left(\mathrm{HML}_{\mathrm{t}}\right)+\beta_{4}\left(\mathrm{RMW}_{\mathrm{t}}\right)+\beta_{5}\left(\mathrm{CMA}_{\mathrm{t}}\right)+\varepsilon_{\mathrm{it}}$ where $R_{i t}$ denotes total return of a stock or portfolio $i$ at time $t$; $R_{f t}$ represents the risk-free rate of return at time $\mathrm{t}$ (proxied by one-month US Treasury bill); $\mathrm{R}_{\mathrm{Mt}}$ is the total market portfolio return at time $t$; $R_{i t}-R_{f t}$ is the expected excess return; $R_{M t}-R_{f t}$ represents the excess return generated over the market portfolio; $\mathrm{SMB}_{\mathrm{t}}$ denotes the size premium (difference between small and big); HML $\mathrm{L}_{\mathrm{t}}$ is the value premium (difference between high and low); $\mathrm{RMW}_{\mathrm{t}}$ denotes the profitability factor (difference in return of the most profitable firms and the least profitable firms); $\mathrm{CMA}_{\mathrm{t}}$ represents the investment factor (difference in return of firms investing conservatively \& those investing aggressively); $\beta_{1, \ldots . ., \beta_{5}}$ are the factor coefficients; and $\alpha_{\text {it }}$ (alpha) represents the access return that remains unexplained by FF3 and FF5 models, respectively.

In this direction we use the S\&P 500 composite index data which is taken from the DataStream and Robert Shiller's database. The US and European business cycle data is taken from NBER and FRED database. This paper uses SPDR® MSCI Europe UCITS ETFs as a proxy to European sectors \& Select Sector SPDR® Fund as a proxy to US sectors as an alternative to US Fama-French sector portfolios to analyse sector rotation strategies, something that an investor would most likely use in real world scenarios. However, the trading period is shorter than Fama-French sectors because of the 
availability of the data. The ETFs data has been collected from Bloomberg and DataStream from 1999 to 2019, consisting of 234 trading intervals (in months).

This paper uses 36 months rolling FF3 and FF5 alphas as a signal for asset reallocation via long only and a long/short strategy. The 36-month rolling FF5 alphas were calculated for the period 1999 to 2019. The long-only strategy buys the sector ETFs in " $t+1$ " month for sectors with positive 36 month rolling FF3 and FF5 alpha respectively in month " $t$ ". On the other hand, the long \& short strategy invests in the sector ETFs in " $t+1$ " month for sectors with positive 36 month rolling FF3 and FF5 alpha respectively in month " $t$ " and sells the sector ETFs in " $t+1$ " month for sectors with negative 36 month rolling FF3 and FF5 alpha respectively in month " $\mathrm{t}$ ". And the portfolio is rebalanced every month using the same framework. This paper also utilizes the Sharpe ratio to compare the risks involved between different strategies along with the Buy-and-Hold strategy. The particular ratio is used as it not only measures the return of the security with respect to the risk taken but also benchmarks it with the returns generated from a risk-free asset, which in true sense is a correct reward measurement matrix. The Buy-and-Hold strategy represents an investment in the benchmark for respective markets, namely S\&P 500 index for the U.S. and Euro Stoxx 50 for the European market.

\section{Results and discussion}

\subsection{Sector rotation based on interest rate and GDP}

Tables 1 and 2 summarise the nature of monetary policy (easing and tightening) from June 1999 to June 2019 for the U.S. and Europe respectively. 
Table 1: The U.S. monetary policy changes (1999 to 2019)

\begin{tabular}{|c|c|c|c|c|c|c|}
\hline $\begin{array}{l}\text { Policy } \\
\text { Period }\end{array}$ & Policy & Start Date & $\begin{array}{l}\text { Start } \\
\text { Rate }\end{array}$ & End Rate & $\begin{array}{l}\text { No. of Rate } \\
\text { Changes }\end{array}$ & $\begin{array}{l}\text { Total } \\
\text { Changes } \\
\text { in Rates }\end{array}$ \\
\hline 1 & Tightening & $30 / 06 / 1999$ & $4.75 \%$ & $6.50 \%$ & 6 & $1.75 \%$ \\
\hline 2 & Easing & $31 / 01 / 2001$ & $6.50 \%$ & $1.00 \%$ & 12 & $-5.50 \%$ \\
\hline 3 & Tightening & $30 / 06 / 2004$ & $1 \%$ & $5.25 \%$ & 17 & $4.25 \%$ \\
\hline 4 & Easing & $28 / 09 / 2007$ & $5.25 \%$ & $0.13 \%$ & 8 & $-5.12 \%$ \\
\hline 5 & Tightening & $31 / 12 / 2015$ & $0.13 \%$ & $\begin{array}{l}2.38 \% \text { as on } \\
28 / 06 / 2019\end{array}$ & $\begin{array}{l}9 r \text { until } \\
28 / 06 / 2019\end{array}$ & $2.25 \%$ \\
\hline
\end{tabular}

The average interest rate during easing and tightening monetary policy in the U.S. was $3.34 \%$ and $3.22 \%$ respectively from 1999 to 2019 with interest rate ranging from $0.13 \%$ in December 2015 to $6.5 \%$ in January 2001. As it becomes apparent from the data monetary policy in the U.S. was mostly contractionary in the sample period. The table reflects the Feds initiative to overcome the financial crisis of 2008 and ease the credit market conditions by using expansionary monetary policy from end of 2007 until December 2015. Also, the Feds have reduced the frequency of changes in monetary policy in the recent past and have implemented the restrictive policy from January 2016 and is continuing with that until today. 
Table 2: European monetary policy changes (1999 to 2019)

\begin{tabular}{|c|c|c|c|c|c|c|}
\hline $\begin{array}{l}\text { Policy } \\
\text { Period }\end{array}$ & Policy & Start Date & $\begin{array}{l}\text { Start } \\
\text { Rate }\end{array}$ & End Rate & $\begin{array}{l}\text { No. of Rate } \\
\text { Changes }\end{array}$ & $\begin{array}{l}\text { Total } \\
\text { Changes } \\
\text { in Rates }\end{array}$ \\
\hline 1 & Easing & $31 / 12 / 2001$ & $3.75 \%$ & $2.00 \%$ & 4 & $-1.75 \%$ \\
\hline 2 & Tightening & $31 / 01 / 2006$ & $2.00 \%$ & $4.25 \%$ & 9 & $2.25 \%$ \\
\hline 3 & Easing & $30 / 11 / 2008$ & $4.25 \%$ & $1.50 \%$ & 7 & $-2.75 \%$ \\
\hline 4 & Tightening & $31 / 05 / 2011$ & $1.00 \%$ & $1.50 \%$ & 2 & $0.50 \%$ \\
\hline 5 & Easing & $31 / 12 / 2011$ & $0.05 \%$ & $\begin{array}{l}0.00 \% \text { as on } \\
28 / 06 / 2019\end{array}$ & $\begin{array}{l}8 r \text { until } \\
28 / 06 / 2019\end{array}$ & $-0.05 \%$ \\
\hline
\end{tabular}

In Europe however the average discount rate during tightening and easing monetary policy periods has been $2.88 \%$ and $1.75 \%$ respectively from 1999 to 2019 with the discount rate ranging from $0.00 \%$ in June 2019 to $4.25 \%$ in January 2006 and November 2008. Unlike the U.S., monetary policy in the EU is dominated by monetary easing over the span of the sample. The table reflects the ECB's initiative to deal with the financial crisis of 2008, and Euro debt crisis at its peak in 2011 and their attempt to ease the credit market conditions by using monetary easing in the respective periods following the crises. The ECB has implemented the easing policy from January 2012 and is still continuing with that till today with current interest rate still being at 0\% from April 2016. Using the change in monetary policy from easing to tightening and vice versa as an indicator for sector rotation between cyclical and non-cyclical (defensive) sectors, the portfolio was rebalanced only 5 times in the last 19 years for both the U.S. and Europe. 
Table 3: Mean sector returns and standard deviations (1999 to 2019)

\begin{tabular}{|l|c|c|c|c|}
\hline & \multicolumn{2}{|c|}{ USA } & \multicolumn{2}{c|}{ EUROPE } \\
\hline & Mean & Std. Dev & Mean & Std. Dev \\
\hline Non Cyclical & & & & \\
\hline Consumer Staples & $9 \%$ & $12 \%$ & $12 \%$ & $15 \%$ \\
\hline Energy & $17 \%$ & $22 \%$ & $5 \%$ & $16 \%$ \\
\hline Health Care & $5 \%$ & $13 \%$ & $7 \%$ & $15 \%$ \\
\hline Utilities & $9 \%$ & $16 \%$ & $9 \%$ & $19 \%$ \\
\hline Average for Non Cyclical & $10 \%$ & $16 \%$ & $8 \%$ & $16 \%$ \\
\hline Cyclical & & & & \\
\hline Consumer Discretionary & $8 \%$ & $20 \%$ & $10 \%$ & $22 \%$ \\
\hline Financial & $11 \%$ & $22 \%$ & $6 \%$ & $25 \%$ \\
\hline Industrial & $11 \%$ & $19 \%$ & $14 \%$ & $23 \%$ \\
\hline Materials & $11 \%$ & $21 \%$ & $16 \%$ & $28 \%$ \\
\hline Technology & $4 \%$ & $25 \%$ & $9 \%$ & $24 \%$ \\
\hline Communication & - & - & $9 \%$ & $18 \%$ \\
\hline Average for Cyclical & $9 \%$ & $21 \%$ & $11 \%$ & $23 \%$ \\
\hline
\end{tabular}

Table 3 presents the annual mean returns and standard deviations of the sector ETFs under consideration for the U.S. and Europe, respectively. The U.S. sectors have shown a wide range of returns from $4 \%$ in technology sector to $17 \%$ in energy sector with a wide volatility ranging from $12 \%$ in consumer staples to $25 \%$ in energy. Similarly, Europe has shown wide range in returns (9\% to $16 \%$ ) and volatility (15\% to $28 \%)$. In general, Cyclical sectors have shown to be more sensitive to market changes which can be observed from high standard deviation in cyclical sectors as compared to non-cyclical sectors in both the U.S. and Europe, which is in line with previous research.

The table reflects that different sectors have generated different returns and have shown different volatility from 1999 to 2019 irrespective of the market, which further signifies 
that a sector rotation strategy if implemented using the right entry and exit signal has the potential to substantially outperform the market returns and also reduce volatility.

Table 4: The U.S. - Sectors performance by monetary periods (1999 to 2019)

\begin{tabular}{|l|c|c|c|c|}
\hline & \multicolumn{2}{|c|}{ Expansionary } & \multicolumn{2}{c|}{ Restrictive } \\
\hline & Mean & Std. Dev & Mean & Std. Dev \\
\hline Non Cyclical & & & & \\
\hline Consumer Staples & $2.39 \%$ & $9.32 \%$ & $2.47 \%$ & $7.66 \%$ \\
\hline Energy & $0.72 \%$ & $16.48 \%$ & $5.73 \%$ & $13.04 \%$ \\
\hline Health Care & $4.88 \%$ & $11.24 \%$ & $2.04 \%$ & $8.18 \%$ \\
\hline Utilities & $-0.48 \%$ & $11.51 \%$ & $5.05 \%$ & $8.35 \%$ \\
\hline Average for Non Cyclical & $1.88 \%$ & $12.14 \%$ & $3.82 \%$ & $9.31 \%$ \\
\hline Cyclical & & & & \\
\hline Consumer Discretionary & $6.11 \%$ & $15.01 \%$ & $2.78 \%$ & $9.89 \%$ \\
\hline Financial & $-0.04 \%$ & $17.87 \%$ & $3.85 \%$ & $11.07 \%$ \\
\hline Industrial & $2.12 \%$ & $15.34 \%$ & $4.59 \%$ & $9.46 \%$ \\
\hline Materials & $3.12 \%$ & $16.94 \%$ & $3.23 \%$ & $10.88 \%$ \\
\hline Technology & $2.22 \%$ & $18.77 \%$ & $4.18 \%$ & $12.91 \%$ \\
\hline Average for Cyclical & $2.71 \%$ & $16.79 \%$ & $3.73 \%$ & $10.84 \%$ \\
\hline
\end{tabular}

Table 5: Europe - Sectors performance by monetary periods (1999 to 2019)

\begin{tabular}{|l|c|c|c|c|}
\hline & \multicolumn{2}{|c|}{ Expansionary } & \multicolumn{2}{c|}{ Restrictive } \\
\hline & Mean & Std. Dev & Mean & Std. Dev \\
\hline Non-Cyclical & & & & \\
\hline Utilities & $7.42 \%$ & $12.97 \%$ & $-0.61 \%$ & $7.52 \%$ \\
\hline Consumer Staples & $8.53 \%$ & $11.02 \%$ & $0.26 \%$ & $6.03 \%$ \\
\hline Health Care & $7.75 \%$ & $11.50 \%$ & $-1.25 \%$ & $5.82 \%$ \\
\hline Energy & $6.82 \%$ & $15.11 \%$ & $-0.97 \%$ & $10.24 \%$ \\
\hline Average for Non Cyclical & $7.63 \%$ & $12.65 \%$ & $-0.64 \%$ & $7.40 \%$ \\
\hline Cyclical & & & & \\
\hline Communication & $2.90 \%$ & $15.35 \%$ & $0.14 \%$ & $7.41 \%$ \\
\hline Consumer Discretionary & $11.11 \%$ & $16.00 \%$ & $-3.02 \%$ & $9.64 \%$ \\
\hline Industrials & $12.09 \%$ & $15.35 \%$ & $-2.82 \%$ & $10.62 \%$ \\
\hline Technology & $8.46 \%$ & $23.35 \%$ & $-3.69 \%$ & $9.86 \%$ \\
\hline Materials & $11.93 \%$ & $16.69 \%$ & $-2.51 \%$ & $12.43 \%$ \\
\hline Financials & $8.70 \%$ & $20.55 \%$ & $-5.61 \%$ & $10.82 \%$ \\
\hline Average for Cyclical & $9.20 \%$ & $17.88 \%$ & $-2.92 \%$ & $10.13 \%$ \\
\hline
\end{tabular}


Tables 4 and 5 summarise the sector returns and their standard deviations for both monetary easing and monetary tightening policies. Table 4 reflects that the market in the U.S. generated very weak results during both easing and tightening monetary policy regimes in sample period. However, cyclical sectors were able to perform better than the non-cyclical sectors during monetary easing regimes and non-cyclical sectors were able to perform better than the cyclical sectors during monetary tightening regimes. These results are in line with the previous studies conducted by Kouzmenko and Nagy (2009) and Conover, et al., (2005). The standard deviation for cyclical sectors is higher than the non-cyclical sectors during both monetary regimes indicating that cyclical sectors are more sensitive to changes in interest rate, these results are similar to Ehrmann and Fratzscher (2004). Basically, simple reallocation between sectors in the U.S. based on changes in monetary policy as an indicator based on previous studies could have slightly improved the returns for this particular sample period.

Table 5 suggests that the market in Europe reflected similar results as the U.S. where cyclical sectors were able to perform better than non-cyclical sectors during monetary easing regime and non-cyclical sectors were able to perform better during monetary tightening regimes in the sample period. Further, the differences in return between easing and tightening monetary policies is higher in cyclical sectors than compared to noncyclical sectors which reflects that the cyclical sectors are more sensitive to changes in interest rate (Ehrmann and Fratzscher, 2004). The average difference between the easing and tightening periods average returns for cyclical sectors in Europe is $12.12 \%(9.20 \%$ $(-2.92 \%)) \&$ for non-cyclical sectors the average difference in returns is $8.27 \%(7.63 \%$ $(-0.64 \%))$. However, the average standard deviation for cyclical sectors in easing as well as tightening monetary policy regime is higher than the non-cyclical sectors. Meaning, 
that simple reallocation between sectors in Europe based on changes in monetary policy as an indicator might have improved the returns but could also have increased the volatility.

Table 6: Sector rotation portfolio vs benchmark (1999 to 2019)

\begin{tabular}{|l|c|c|c|c|c|c|}
\hline & \multicolumn{3}{|c|}{ USA } & \multicolumn{3}{c|}{ EUROPE } \\
\hline & Mean & Std dev & Sharpe ratio & Mean & Std dev & Sharpe ratio \\
\hline Portfolio & $6.73 \%$ & $16.60 \%$ & 0.406 & $11.14 \%$ & $15.24 \%$ & 0.73 \\
\hline Benchmark & $7.04 \%$ & $14.70 \%$ & 0.48 & $8.53 \%$ & $21.76 \%$ & 0.39 \\
\hline & & - & - & $2.61 \%$ & - & - \\
\hline
\end{tabular}

Notes: Mean percentages denote annual returns.

Table 6 compares the mean return, standard deviation and sharpe ratio of the sector rotation portfolio \& benchmark for both the U.S. and Europe respectively. According to the table the difference between (annualized) mean return of the sector rotation strategy portfolio and the benchmark portfolio is $-0.31 \%$. Thereby, making the strategy economically insignificant. For US, the sector rotation portfolio generates lower returns than the benchmark along with higher standard deviation, resulting in a poor sharpe ratio over the sample period. However, table 6 also suggests that the sector rotation portfolio based on European sector ETFs is able to generate superior returns than the benchmark portfolio with significantly lower standard deviation, making the sector rotation an economically significant venture. Higher mean returns and lower standard deviation results in a net higher Sharpe ratio of 0.73 for the sector rotation portfolio, which is roughly over two times more than that of benchmark portfolio.

The added advantage of sector rotation strategy based on monetary policy as a switching indicator is that it doesn't require to rebalance portfolio frequently which further reduces 
transaction costs. During the sample period used in this section, the portfolio was rebalanced only 5 times for both US and Europe.

We decided against using the results that corresponds to changes in GDP as an indicator for switching between sectors because the historical data revealed that it leads to very high volatility in the stock portfolio (see Table 2 and 3 in the appendix). This might to some extent be attributed to the frequency of the data, i.e. quarterly, which fails to reflect the true market sentiment over certain periods.

\subsection{Sector rotation based on momentum and consumer sentiment}

Figure 1: Europe - Momentum based sector rotation strategy performance

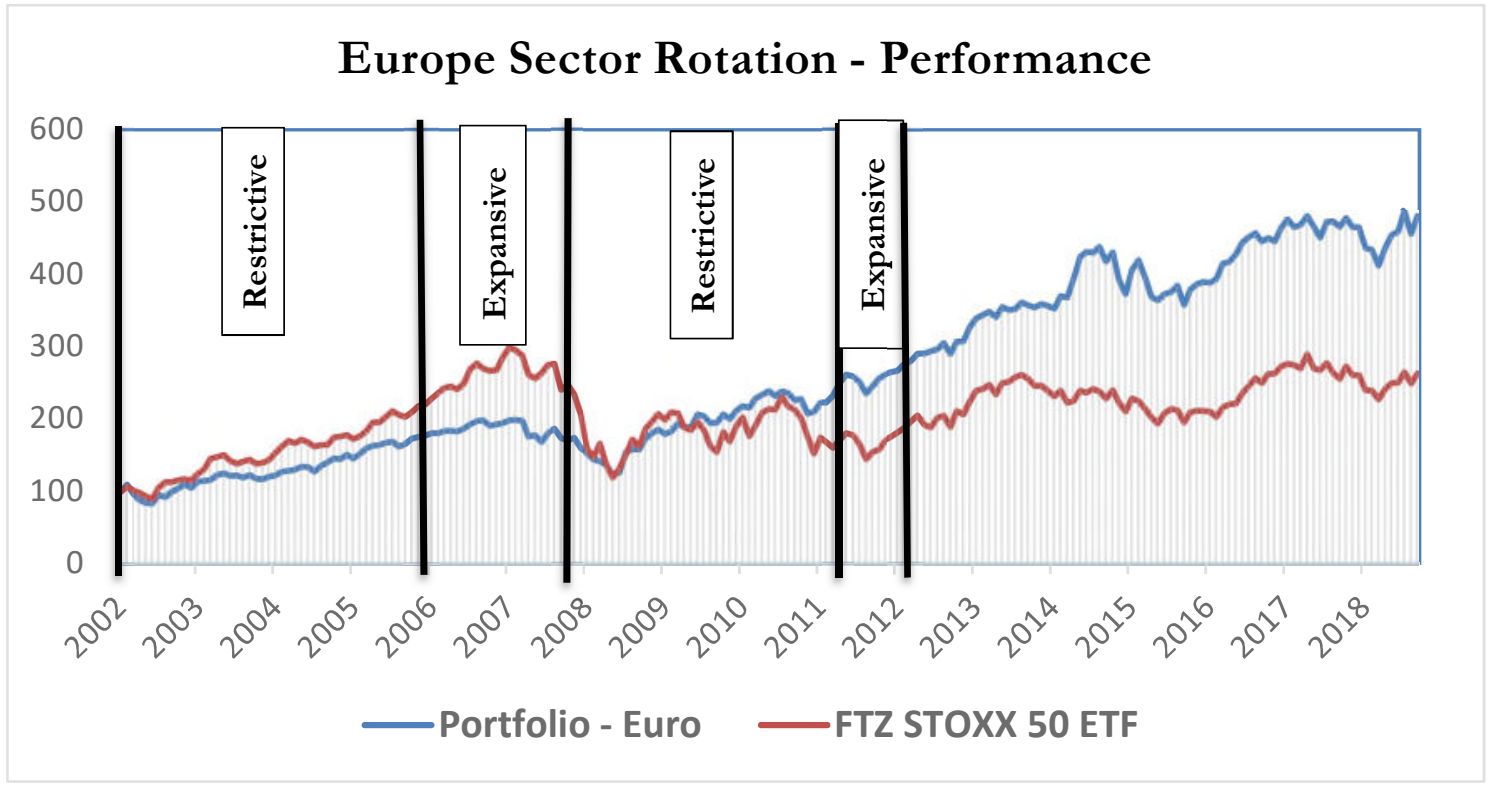




\section{Figure 2: The U.S. - Momentum based sector rotation strategy performance}

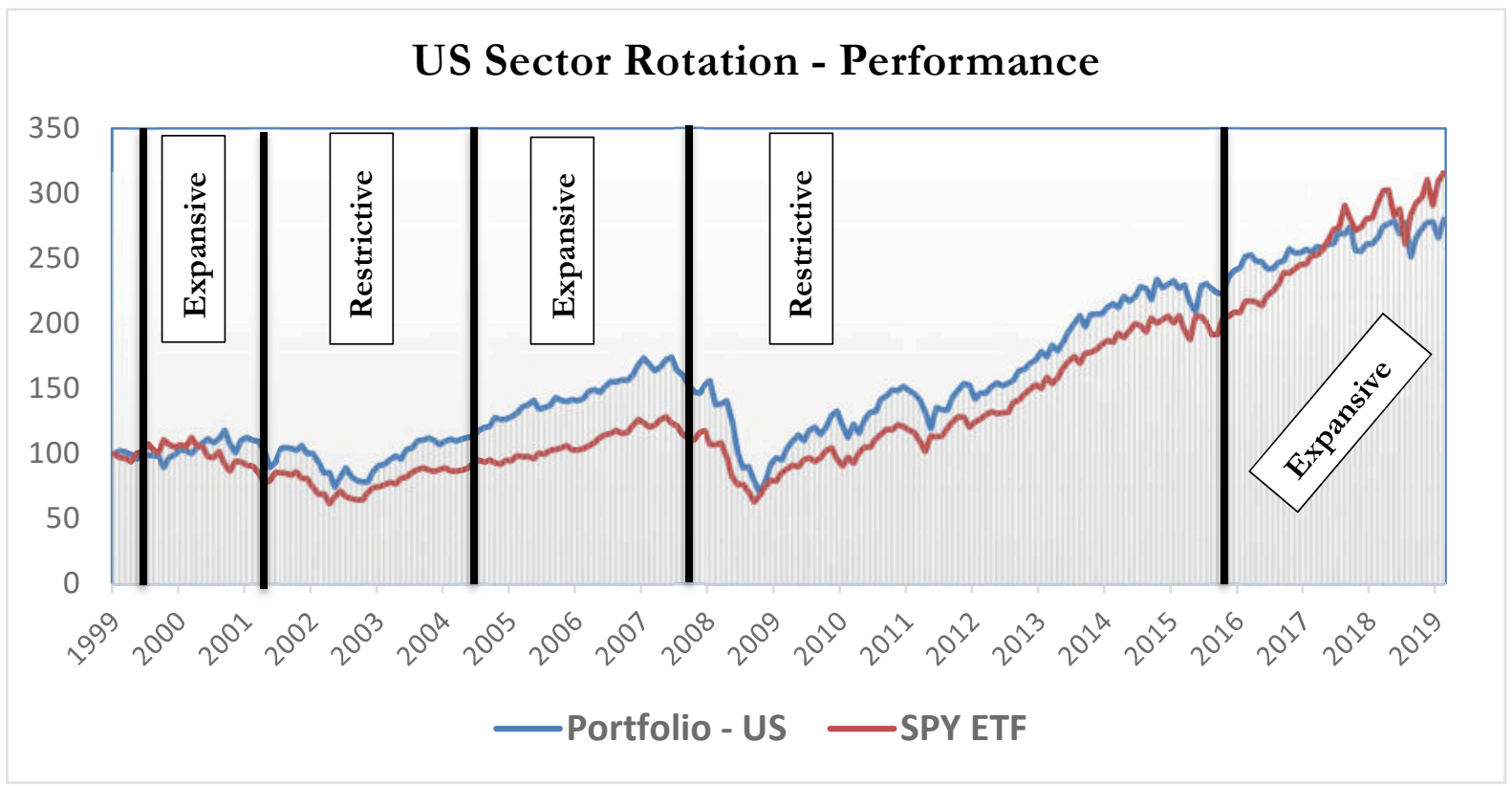

Figures 1 and 2 illustrate the performance of the strategy in monetary easing and monetary tightening regimes for Europe and the U.S., respectively. The portfolios for both the markets have managed to capture the trend during monetary tightening policy regime and have continued to outperform the market during those, especially for Europe. The strategy apart from increasing the returns roughly two folds, also reduces the standard deviation of the returns which can be noticed from less sharp turns in graph for returns of the sector portfolio as compared to the benchmark portfolio. An interesting trend to observe here is that right after announcement of monetary tightening, most of the times the returns start to decline for both the markets and after an announcement of monetary easing there is a trend of short-term increase in the returns. These results are in line with the study conducted by Jensen and Johnson (1995). These trends could be attributed to the psychological behaviour of investors who take monetary easing as a sign of growth and monetary tightening as a sign of decline in economy. 
Tables 7 and 8 use t-tests to analyse the returns of the winner portfolio strategies in the U.S. and Europe respectively. The table represents the monthly return, annual return, $p$ value associated with single sample t-test, standard deviation, and Sharpe ratio.

Table 7: The U.S. winner portfolio

\begin{tabular}{|c|c|c|c|c|c|c|}
\hline & & $K=1$ & $K=3$ & $K=6$ & $K=12$ & S\&P 500 \\
\hline \multirow{5}{*}{$J=1$} & Monthly return & $0 \%$ & $0 \%$ & $0 \%$ & $0 \%$ & $0 \%$ \\
\hline & Annual return & $3 \%$ & $4 \%$ & $0 \%$ & $-2 \%$ & $4 \%$ \\
\hline & $\mathrm{p}$ value & $41 \%$ & $18 \%$ & $91 \%$ & $55 \%$ & $16 \%$ \\
\hline & Std Dev. & $4 \%$ & $4 \%$ & $3 \%$ & $4 \%$ & $4 \%$ \\
\hline & $\begin{array}{l}\text { Sharpe ratio } \\
\text { (monthly) }\end{array}$ & 0.05 & 0.09 & 0.01 & -0.04 & 0.09 \\
\hline & & $K=1$ & $K=3$ & $K=6$ & $K=12$ & S\&P 500 \\
\hline \multirow{5}{*}{$\mathrm{J}=3$} & Monthly return & $0 \%$ & $0 \%$ & $1 \%$ & $1 \%$ & $0 \%$ \\
\hline & Annual return & $6 \%$ & $5 \%$ & $6 \%$ & $6 \%$ & $4 \%$ \\
\hline & $\mathrm{p}$ value & $9 \%$ & $12 \%$ & $8 \%$ & $9 \%$ & $16 \%$ \\
\hline & Std Dev. & $4 \%$ & $4 \%$ & $4 \%$ & $5 \%$ & $4 \%$ \\
\hline & $\begin{array}{l}\text { Sharpe ratio } \\
\text { (monthly) }\end{array}$ & 0.11 & 0.10 & 0.11 & 0.11 & 0.09 \\
\hline & & $K=1$ & $K=3$ & $K=6$ & $K=12$ & S\&P 500 \\
\hline \multirow{5}{*}{$J=6$} & Monthly return & $0 \%$ & $0 \%$ & $0 \%$ & $0 \%$ & $0 \%$ \\
\hline & Annual return & $6 \%$ & $5 \%$ & $6 \%$ & $6 \%$ & $4 \%$ \\
\hline & $\mathrm{p}$ value & $9 \%$ & $11 \%$ & $10 \%$ & $11 \%$ & $16 \%$ \\
\hline & Std Dev. & $4 \%$ & $4 \%$ & $4 \%$ & $5 \%$ & $4 \%$ \\
\hline & $\begin{array}{l}\text { Sharpe ratio } \\
\text { (monthly) }\end{array}$ & 0.11 & 0.10 & 0.11 & 0.10 & 0.09 \\
\hline & & $K=1$ & $K=3$ & $K=6$ & $K=12$ & S\&P 500 \\
\hline \multirow{5}{*}{$J=12$} & Monthly return & $0 \%$ & $0 \%$ & $0 \%$ & $0 \%$ & $0 \%$ \\
\hline & Annual return & $5 \%$ & $5 \%$ & $3 \%$ & $5 \%$ & $4 \%$ \\
\hline & $\mathrm{p}$ value & $13 \%$ & $15 \%$ & $35 \%$ & $16 \%$ & $16 \%$ \\
\hline & Std Dev. & $4 \%$ & $4 \%$ & $4 \%$ & $4 \%$ & $4 \%$ \\
\hline & $\begin{array}{l}\text { Sharpe ratio } \\
\text { (monthly) }\end{array}$ & 0.10 & 0.09 & 0.06 & 0.09 & 0.09 \\
\hline
\end{tabular}


Table 8: European winner portfolio

\begin{tabular}{|c|c|c|c|c|c|c|}
\hline & & $K=1$ & $K=3$ & $K=6$ & $K=12$ & EURO STOXX 50 \\
\hline \multirow{5}{*}{$J=1$} & Monthly return & $1 \%$ & $1 \%$ & $1 \%$ & $0 \%$ & $1 \%$ \\
\hline & Annual return & $8 \%$ & $7 \%$ & $11 \%$ & $-5 \%$ & $8 \%$ \\
\hline & $\mathrm{p}$ value & $5 \%$ & $6 \%$ & $0 \%$ & $8 \%$ & $15 \%$ \\
\hline & Std Dev. & $4 \%$ & $5 \%$ & $4 \%$ & $3 \%$ & $6 \%$ \\
\hline & Sharpe ratio (monthly) & 0.14 & 0.13 & 0.21 & -0.12 & 0.10 \\
\hline & & $\mathrm{K}=1$ & $K=3$ & $K=6$ & $K=12$ & EURO STOXX 50 \\
\hline \multirow{5}{*}{$\mathrm{J}=3$} & Monthly return & $1 \%$ & $1 \%$ & $1 \%$ & $0 \%$ & $1 \%$ \\
\hline & Annual return & $10 \%$ & $8 \%$ & $7 \%$ & $6 \%$ & $8 \%$ \\
\hline & $\mathrm{p}$ value & $1 \%$ & $3 \%$ & $5 \%$ & $9 \%$ & $15 \%$ \\
\hline & Std Dev. & $4 \%$ & $4 \%$ & $4 \%$ & $4 \%$ & $6 \%$ \\
\hline & Sharpe ratio (monthly) & 0.19 & 0.16 & 0.14 & 0.12 & 0.10 \\
\hline & & $K=1$ & $K=3$ & $K=6$ & $K=12$ & EURO STOXX 50 \\
\hline \multirow{5}{*}{$J=6$} & Monthly return & $0 \%$ & $0 \%$ & $1 \%$ & $1 \%$ & $1 \%$ \\
\hline & Annual return & $4 \%$ & $6 \%$ & $7 \%$ & $9 \%$ & $8 \%$ \\
\hline & $\mathrm{p}$ value & $3 \%$ & $10 \%$ & $5 \%$ & $2 \%$ & $15 \%$ \\
\hline & Std Dev. & $2 \%$ & $4 \%$ & $4 \%$ & $4 \%$ & $6 \%$ \\
\hline & Sharpe ratio (monthly) & 0.16 & 0.12 & 0.14 & 0.17 & 0.10 \\
\hline & & $\mathrm{K}=1$ & $K=3$ & $K=6$ & $K=12$ & EURO STOXX 50 \\
\hline \multirow{5}{*}{$\mathrm{J}=12$} & Monthly return & $0 \%$ & $1 \%$ & $1 \%$ & $1 \%$ & $1 \%$ \\
\hline & Annual return & $4 \%$ & $7 \%$ & $7 \%$ & $8 \%$ & $8 \%$ \\
\hline & $\mathrm{p}$ value & $4 \%$ & $5 \%$ & $5 \%$ & $4 \%$ & $15 \%$ \\
\hline & Std Dev. & $2 \%$ & $4 \%$ & $4 \%$ & $4 \%$ & $6 \%$ \\
\hline & Sharpe ratio (monthly) & 0.15 & 0.14 & 0.14 & 0.15 & 0.10 \\
\hline
\end{tabular}

On the basis of the evidence reported in tables 7 and table 8 , the following conclusions can be drawn for the U.S. and European sector rotation strategy based on momentum:

More specifically, according to table 8 the returns of the U.S. Sector rotation strategy based on momentum are not significantly different from zero for all 16 portfolios $(\mathrm{J}=1$, $3,6,12$ and $K=1,3,6,12)$. In other words, momentum effect wasn't significant for the sample period and sectors under consideration in this paper for the U.S. and in contrast it suggested towards the existence of a contrarian effect. However, table 8 shows that the returns of European Sector rotation strategy based on momentum are significantly different from zero for the majority of portfolios. In other words, momentum effect has 
shown statistical significance for the sample period and sectors under consideration in this paper for Europe and in contrast it favoured the non-existence of contrarian effect in European Market. For distinct values of J, the following results were found:

1. The high $p$ value for $J=1$ (formation period) for both the U.S. and Europe is in line with Jegadeesh (1990) and Lehmann (1990) which suggest the existence of strong contrarian effect for short holding/formation period. The average return for the U.S. sector-based strategy for $J=1$ and $K=1,3,6,12$ is mere $1.5 \%$ further suggesting the weak impact of momentum effect in short term.

2. For formation period "J" $=3$, the momentum effect has been the most prominent among all the formation periods followed by "J" $=6$ months for both the U.S. and Europe.

3. Almost all the portfolios generated positive average returns for the strategy with the exception of $\mathrm{J}=1$ and $\mathrm{K}=12$ portfolio which generated negative returns for both the markets. Further emphasising on the failure of short term returns to capture momentum effect.

No statistically significant pattern in the volatility of the returns (standard deviation) for neither the U.S. nor Europe was observed during the analysis. The momentum effect was statistically strong in the European Market in comparison to the U.S. Market and therefore resulted in higher average returns for all the portfolios and most importantly also generated lower volatility (standard deviation). Thereby, generating more sharpe ratio for all the "J" \& "K" combination portfolios.

Momentum effect in the U.S.: Table 7 suggests that all of the possible combinations of $\mathrm{J}=1$ have resulted in the least sharpe ratio in comparison to the benchmark and all other values of $\mathrm{J}$, meaning that the momentum effect is the weakest at 1-month interval. This is 
in contradiction to the results of Moskowitz and Grinblatt (1999) which could be attributed to either the use of different time frame or the use of different assets in the two studies. However, at 3-month and 6-month interval, momentum effect has resulted in a net higher sharpe ratio. The returns have increased by more than $2 \%$ annually with almost similar standard deviation (volatility) for $\mathrm{J}=3$ and $\mathrm{J}=6$ with respect to the benchmark. At 12-month time interval the momentum effect can still be felt (net increase of $1 \%$ returns annually then the benchmark) but can be considered dissipating when compared to the momentum effects at 3- and 6-month time intervals.

Momentum effect in Europe: Table 8 reports that 15 out of 16 combination of sector rotation strategies based on momentum have been able to generate a higher sharpe ratio than the benchmark (Euro Stoxx 50), however most of this credit could be attributed to the ability of these strategies to reduce volatility than their ability to generate superior returns as only 4 out of 16 of these combinations were able to generate abnormal returns. This could potentially reflect the absence of momentum in the European market.

Figures, 1 to 8 in the appendix illustrate the performance of all these momentum-based strategies $(\mathrm{J}=1,3,6 \& 12$ and $\mathrm{K}=1,3,6 \& 12)$ over the sample period under consideration. Tables 11 and 12 report the descriptive statistics of the sector portfolios monthly excess returns $\left(\mathrm{R}_{\mathrm{it}}-\mathrm{R}_{\mathrm{ft}}\right)$ from 1999 to 2019 . Out of all the 9 sectors in the U.S. only Materials reflected positive skewness and only Technology and Financials out of the 10 sectors in Europe reflected positive skewness. This signifies that the chances of sector returns taking extreme values is mostly towards the left tail. In the U.S. - Consumer discretionary exhibited the highest mean monthly excess return of $0.76 \%$, while in Europe - Industrials exhibited the highest mean monthly excess return of $0.62 \%$. In both markets, the technology sector appeared to be the most volatile sector between 1999 to 2019 . 
In this paper as we also purport to gain further insights into the impact of consumer sentiments, which is believed to drive momentum, we utilize OECD's consumer confidence indicator $(\mathrm{CCI})$ as a timing tool to switch between sectors. The $\mathrm{CCI}$ indicator reflects the potential of peoples' consumption and savings based on their expected financial situation, general consumer sentiment regarding the future of the market, level of employment and savings potential. A score over 100 reflects a bullish attitude among consumers which results in less savings and more expenditure. However, a value below 100 reflects bearish attitude among consumers which results in more savings and less expenditure.

Below we provide an analysis of the monthly returns of the sector-based ETFs for the U.S. and Europe both from 1999 to 2019 and compare it with the monthly returns of their benchmarks, namely, S\&P 500 Index and Stoxx respectively. To evaluate the effectiveness of consumer sentiment as an indicator for sector rotation we adopt the following methodological framework. In this direction we construct an equity portfolio by a) investing in an equally weighted portfolio comprising of all the cyclical sector ETFs in periods where the CCI was over 100, and b) investing in an equally weighted portfolio comprising of all the defensive (non-cyclical) sector ETFs during periods where the CCI was below 100 .

Table 9: Sector rotation portfolio vs benchmark (1999 to 2019)

\begin{tabular}{|l|c|c|c|c|c|c|}
\hline & \multicolumn{3}{|c|}{ USA } & \multicolumn{3}{c|}{ EUROPE } \\
\hline & Mean & Std dev & Sharpe ratio & Mean & Std dev & Sharpe ratio \\
\hline Portfolio & $6.70 \%$ & $60.73 \%$ & 0.11 & $5.06 \%$ & $59.81 \%$ & 0.08 \\
\hline Benchmark & $7.04 \%$ & $14.70 \%$ & 0.48 & $8.53 \%$ & $21.76 \%$ & 0.39 \\
\hline & & - & - & $-3.47 \%$ & - & - \\
\hline
\end{tabular}


Notes: Mean percentages denote annual returns.

Table 9 compares the mean return, standard deviation and Sharpe ratio of the sector rotation portfolio \& benchmark for both the U.S. and Europe respectively.

In particular, table 9 suggests that the difference between (annualized) mean return of the sector rotation strategy portfolio and the benchmark portfolio is $-0.34 \%$, hence, making the strategy economically insignificant. For the U.S., the sector rotation portfolio generates lower returns than the benchmark along with higher standard deviation, resulting in a poor Sharpe ratio over the sample period. Further, table 11 also shows that the sector rotation portfolio based on European sector ETFs generated even poorer results with the benchmark having an excess return of $3.47 \%$ annually over the portfolio with significantly higher standard deviation, making the sector rotation an economically insignificant venture.

In both the cases the benchmark was able to outperform the portfolio and had relatively far lower volatility. This would lead us to infer that the CCI might not be an accurate indicator for switching between sectors in any of the two economies.

\subsection{Sector rotation based on rolling regression}

Rolling regression with a 36-month window based on Fama and French 5 Factor Model was executed for 9 Sector ETFs for the U.S. and 10 European Sector ETFs over the sample period. Alpha here represents the returns that remain unexplained by the 5 factors used in Fama and French five factor model. Table 11 and 12 summarises the annualised mean of rolling five factor sector wise alphas and their corresponding standard deviations 
for US and Europe respectively. The number of 36 month rolling regression-based alphas for each sector in US and Europe are 211 and 176 respectively.

Table 10 suggests that the highest mean alpha observed in US is for Energy sector (15\%) and HealthCare sector (14\%) while the lowest mean alpha is for Industrial Sector (-56\%) and Financial sector $(-42 \%)$. Within the 9 sectors under observation in this section, the overall mean alpha is negative $(-17 \%)$. This finding is contrary to that of Dellva, DeMaskey and Smith (2001) where the authors found a net positive alpha for 35 Fidelity sector funds in US. However, the difference in results may be potentially attributed to two facts, firstly the use of Sector ETFs in this paper unlike the specialised mutual funds (sector funds) used in Dellva, DeMaskey and Smith (2001) and secondly to the different sample period used for analysis, where the aforementioned authors used the sample period from 1989 to 1998 , whereas this paper focuses on sector performance from 1999 to 2019. However, these findings are similar to relatively recent literature focusing on sector performance and sector selectivity like the findings of Sarwara, Mateusa \& Todorovic (2017) and Dou et al. (2014), both of which reported a net positive alpha for energy and health care sectors; and negative alphas for consumer staples and industrial sectors.

Table 11 reflects that the net overall rolling five factor alphas for European sectors is $30 \%$. The highest observed mean alpha is for Healthcare (75\%) and the lowest mean alpha is for Energy (-46\%). The sectors in Europe in comparison to those in US have been successful in generating net positive alpha for the given sample period with 9 out of 10 European sector ETFs with net positive alpha in comparison to only 2 out of 9 sectors with positive alpha in the U.S. 
Table 10: Rolling regression summary for the U.S. sectors

\begin{tabular}{|c|c|c|c|}
\hline Sector & Sector ETF & Mean Alpha & Std Dev. \\
\hline Consumer Discretionary & XLY US Equity & $-6 \%$ & $36 \%$ \\
\hline Consumer Staples & XLP US Equity & $-16 \%$ & $41 \%$ \\
\hline Energy & XLE US Equity & $15 \%$ & $42 \%$ \\
\hline Financial & XLF U S Equity & $-42 \%$ & $50 \%$ \\
\hline Health Care & XLV US Equity & $14 \%$ & $32 \%$ \\
\hline Industrial & XLI U S Equity & $-56 \%$ & $63 \%$ \\
\hline Materials & XLB US Equity & $-22 \%$ & $40 \%$ \\
\hline Technology & XLK US Equity & $-18 \%$ & $22 \%$ \\
\hline Utilities & XLU US Equity & $-20 \%$ & $61 \%$ \\
\hline & Net & $-17 \%$ & $43 \%$ \\
\hline
\end{tabular}

Table 11: Rolling regression summary for the European sectors

\begin{tabular}{|l|l|r|r|}
\hline Sector & ETF & Mean Alpha & Std Dev. \\
\hline Consumer Discretionary & STR FP Equity & $25 \%$ & $106 \%$ \\
\hline Consumer Staples & STS FP Equity & $45 \%$ & $51 \%$ \\
\hline Energy & STN FP Equity & $-46 \%$ & $101 \%$ \\
\hline Financials & STZ FP Equity & $51 \%$ & $106 \%$ \\
\hline Health Care & STW FP Equity & $75 \%$ & $83 \%$ \\
\hline Industrials & STQ FP Equity & $48 \%$ & $57 \%$ \\
\hline Technology & STK FP Equity & $56 \%$ & $122 \%$ \\
\hline Materials & STP FP Equity & $16 \%$ & $49 \%$ \\
\hline Communication & STT FP Equity & $14 \%$ & $78 \%$ \\
\hline Utilities & STU FP Equity & $18 \%$ & $50 \%$ \\
\hline & Net & $\mathbf{3 0 \%}$ & $\mathbf{8 0 \%}$ \\
\hline
\end{tabular}

In order to further understand and illustrate the performance of each of the analysed sectors over time, charts have been plotted for rolling Fama and French 5 factor alpha for US and Europe over the sample period. As it can be seen clearly in Figure 3, the Industrial and Technology sectors appear to have performed poorly throughout the sample period except for 2004-2005 and 2007-2008 period. Energy sector was recorded with the highest positive alpha during 2001 to 2003 period and has been declining ever after, up until recently. Utilities sector seem to have a cyclical alpha during the sample period with 
alternate periods of positive and negative alphas. Healthcare sector has performed relatively well during the sample period with only brief periods with negative alphas.

Figure 4 shreds some light on the relative performance of sector ETFs in Europe. Technology sector has seen exceptional performance with the highest recorded positive alphas between 2004 and 2005 and has performed well during the sample period except from 2005-2010. Financials sector has performed worst from 2007 to 2009 which is consistent with the 2008 financial crisis and has recovered slowly over the time. Similar to US, Utilities sector in Europe seems to have followed a cyclical pattern with alternate periods of positive and negative alphas. Communication, Technology and Healthcare sectors have performed well from 2010 onwards. 
Figure 3: 36 Month Rolling Alpha Trend - USA

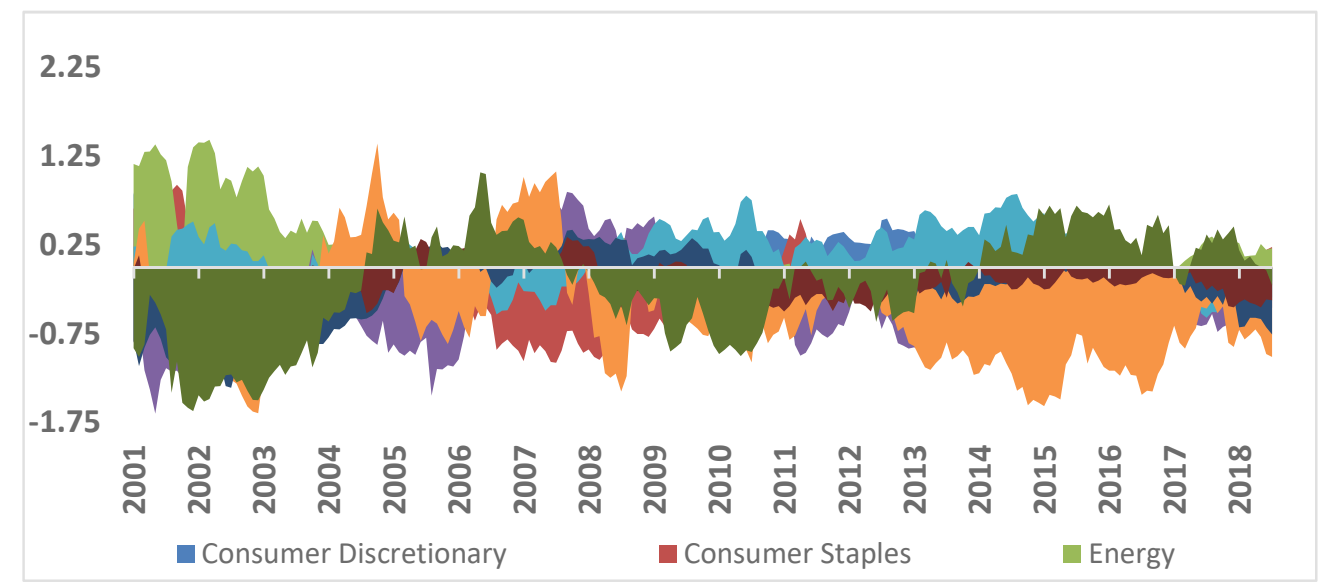

Figure 4: 36 Month Rolling Alpha Trend - Europe

2.5

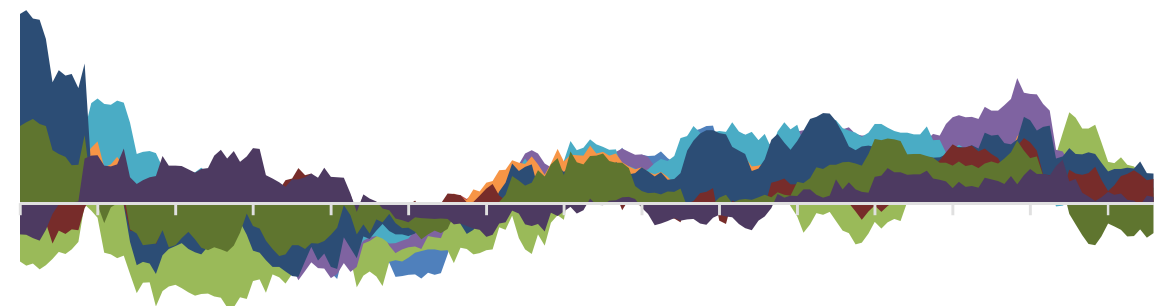

$-2.5$

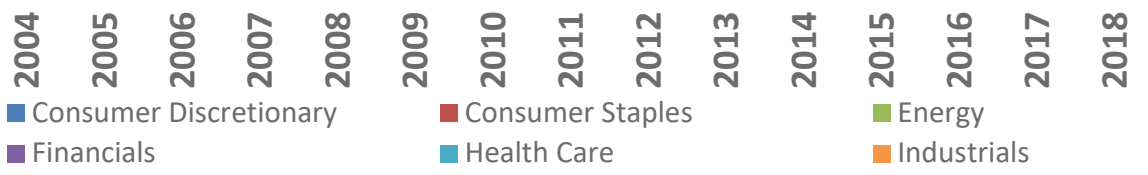

The results so far point towards the difference between risk adjusted performance of sector ETFs as per FF5 and FF3 model. The difference further suggests that both the asset pricing model incorporates and present different information about the asset performance. Tables 13 and 14 summarises the Ordinary Least Square (OLS) regression results for FF5 and FF3 models for both the U.S. and European sectors respectively for the period under consideration from 1999 to 2019. The tables below capture the R-square, alphas, coefficients of the factors associated with the three factor and five factor asset pricing models namely, Market factor, SMB factor, HML factor, RMW factor and CMA factor. 
The value in parenthesis represents the $\mathrm{p}$ value which reflects the statistical significance of each factor.

The following inferences can be drawn from Table 12 for the U.S.:

- Table 12 suggests that 3 out of 9 U.S. sector alphas (Financials, Materials and Technology) are statistically significant for five factor model, at $90 \%$ significance level. However, only 1 sector alpha (Consumer Staples) is statistically significant for three factor model, at 99\% significance level.

- In case of Five Factor Model for US, majority of the sectors show underperformance (negative alphas) after accounting for market, size, value, investment and profitability risk factors except for Energy Sector and Healthcare sector. However, in case of three factor model for US, after incorporating market, size and value risk twice the number of sectors had positive alphas representing outperformance but none of them was statistically significant. Moreover, majority of the betas for both the models in US were found to be statistically significant.

- The market, size and value factors were found to be statistically more significant in case of Five Factor model as compared to three factor model. Also, the adjusted R-square of five factor model was found to be higher than that of three factor model for each of the ten sectors in the sample period. This suggests that Five Factor Model is a better suited to explain US sector returns from a statistical significance point of view.

- However, the insignificant alphas suggest that Market, Size, Value, Profitability, and Investment factors are not enough to explain some sector returns.

The following inferences can be drawn from Table 13 for Europe: 
- Table 13 reflects that 3 out of 10 European sector alphas (Healthcare, Technology and Communication) are statistically significant for five factor model at $90 \%$, $95 \%$ and $90 \%$ significance level respectively. However, only 2 sector alphas (Consumer Staples and Healthcare) are statistically significant for three factor model at $95 \%$ and $90 \%$ significance level respectively.

- In case of Five Factor Model for Europe, majority of the sectors show outperformance after adjusting for market, size, value, investment and profitability risk factors except for Energy sector. However, in case of three factor model for US, after incorporating market, size and value risk twice the number of sectors had negative alphas (Financials and Technology) representing underperformance but neither of them was statistically significant. Moreover, majority of the betas for both the models in Europe were found to be statistically significant.

- The market, size and value factors were found to be statistically more significant in case of Five Factor model as compared to three factor model. Also, the adjusted R-square of five factor model was found to be higher than that of three factor model for each of the ten sectors in the sample period. This suggests that like in case of US, Five Factor Model is also better suited to explain European sector returns from a statistical significance point of view.

- However, here also large number of statistically insignificant alphas suggests that Market, Size, Value, Profitability, and Investment factors are not enough to explain some sector returns. 
Table 12: OLS regression estimates - US Sectors.

\begin{tabular}{|c|c|c|c|c|c|c|c|c|}
\hline & Model & Alpha & $\begin{array}{c}\text { Market } \\
\text { Beta }\end{array}$ & $\begin{array}{l}\text { SMB } \\
\text { Beta }\end{array}$ & $\begin{array}{c}\text { HML } \\
\text { Beta }\end{array}$ & $\begin{array}{c}\text { RMW } \\
\text { Beta }\end{array}$ & $\begin{array}{c}\text { CMA } \\
\text { Beta }\end{array}$ & $\mathbf{R}^{2}$ \\
\hline \multirow{2}{*}{$\begin{array}{c}\text { Consumer } \\
\text { Discretionary }\end{array}$} & 5 Factor & $\begin{array}{c}0.348 \\
(0.237)\end{array}$ & $\begin{array}{c}0.668^{* * *} \\
(0.000)\end{array}$ & $\begin{array}{l}-0.197 \\
(0.185)\end{array}$ & $\begin{array}{l}-0.100 \\
(0.605)\end{array}$ & $\begin{array}{c}-0.159 \\
0.481\end{array}$ & $\begin{array}{c}-0.637 * * * \\
(0.007)\end{array}$ & $50.60 \%$ \\
\hline & 3 Factor & $\begin{array}{l}0.123 \\
0.655 \\
\end{array}$ & $\begin{array}{c}0.762^{* * *} \\
(0.000)\end{array}$ & $\begin{array}{c}-0.127 \\
0.386 \\
\end{array}$ & $\begin{array}{c}-0.286^{* *} \\
(0.043)\end{array}$ & $\begin{array}{l}- \\
- \\
\end{array}$ & $\begin{array}{l}- \\
-\end{array}$ & $48.63 \%$ \\
\hline \multirow{2}{*}{$\begin{array}{l}\text { Consumer } \\
\text { Staples }\end{array}$} & 5 Factor & $\begin{array}{l}0.247 \\
0.258\end{array}$ & $\begin{array}{c}0.460 * * * \\
(0.000)\end{array}$ & $\begin{array}{c}-0.293^{* * *} \\
(0.008)\end{array}$ & $\begin{array}{c}-0.382 * * * \\
(0.008)\end{array}$ & $\begin{array}{c}0.590 * * * \\
(0.001)\end{array}$ & $\begin{array}{l}0.052 \\
0.765\end{array}$ & $38.68 \%$ \\
\hline & 3 Factor & $\begin{array}{c}0.508^{* *} \\
(0.014) \\
\end{array}$ & $\begin{array}{c}0.417^{* * *} \\
(0.000)\end{array}$ & $\begin{array}{c}-0.272^{* * *} \\
(0.014)\end{array}$ & $\begin{array}{c}-0.637 * * * \\
(0.000) \\
\end{array}$ & $\begin{array}{l} \\
- \\
\end{array}$ & $\begin{array}{l}- \\
- \\
\end{array}$ & $35.19 \%$ \\
\hline \multirow{2}{*}{ Energy } & 5 Factor & $\begin{array}{l}-0.289 \\
(0.365)\end{array}$ & $\begin{array}{c}0.556^{* * *} \\
(0.000)\end{array}$ & $\begin{array}{c}-0.422^{* * *} \\
(0.009)\end{array}$ & $\begin{array}{c}0.701^{* * *} \\
(0.001)\end{array}$ & $\begin{array}{c}1.204^{* * *} \\
(0.000)\end{array}$ & $\begin{array}{l}-0.289 * \\
(0.056) \\
\end{array}$ & $38.55 \%$ \\
\hline & 3 Factor & $\begin{array}{c}0.115 \\
(0.712)\end{array}$ & $\begin{array}{c}0.544^{* * *} \\
(0.000)\end{array}$ & $\begin{array}{l}-0.273 \\
(0.102) \\
\end{array}$ & $\begin{array}{c}-0.033 \\
0.835 \\
\end{array}$ & $\begin{array}{l}- \\
-\end{array}$ & $\begin{array}{l}- \\
- \\
\end{array}$ & $30.17 \%$ \\
\hline \multirow{2}{*}{ Financials } & 5 Factor & $\begin{array}{c}0.261 \\
(0.312) \\
\end{array}$ & $\begin{array}{c}0.682^{* * *} \\
(0.000)\end{array}$ & $\begin{array}{c}-0.538^{* * *} \\
(0.000)\end{array}$ & $\begin{array}{c}0.705^{* * *} \\
(0.000)\end{array}$ & $\begin{array}{c}-0.968^{* * * *} \\
(0.000)\end{array}$ & $\begin{array}{c}-1.206^{* * *} \\
(0.000)\end{array}$ & $75.28 \%$ \\
\hline & 3 Factor & $\begin{array}{l}-0.477 * \\
(0.078)\end{array}$ & $\begin{array}{c}0.905^{* * *} \\
(0.000)\end{array}$ & $\begin{array}{c}-0.438^{* * *} \\
(0.003)\end{array}$ & $\begin{array}{c}0.632^{* * *} \\
(0.000) \\
\end{array}$ & $\begin{array}{l} \\
- \\
\end{array}$ & $\begin{array}{l} \\
- \\
\end{array}$ & $67.86 \%$ \\
\hline \multirow{2}{*}{ Health Care } & 5 Factor & $\begin{array}{l}0.480^{*} \\
(0.057)\end{array}$ & $\begin{array}{c}0.302^{* * *} \\
(0.000)\end{array}$ & $\begin{array}{c}-0.432^{* * * *} \\
(0.001)\end{array}$ & $\begin{array}{c}-0.552 * * * \\
(0.001)\end{array}$ & $\begin{array}{l}-0.191 \\
(0.322) \\
\end{array}$ & $\begin{array}{c}-0.015 \\
0.938 \\
\end{array}$ & $24.80 \%$ \\
\hline & 3 Factor & $\begin{array}{l}0.366 \\
0.113 \\
\end{array}$ & $\begin{array}{c}0.321^{* * *} \\
(0.000)\end{array}$ & $\begin{array}{c}-0.448^{* * *} \\
(0.000)\end{array}$ & $\begin{array}{c}-0.501 * * * \\
(0.000)\end{array}$ & $\begin{array}{l}- \\
- \\
\end{array}$ & $\begin{array}{l}- \\
- \\
\end{array}$ & $24.54 \%$ \\
\hline Industrials & 5 Factor & $\begin{array}{l}0.329 \\
(0.209 \\
\end{array}$ & $\begin{array}{c}0.762^{* * *} \\
(0.000)\end{array}$ & $\begin{array}{c}0.088 \\
(0.508) \\
\end{array}$ & $\begin{array}{l}-0.134 \\
(0.437) \\
\end{array}$ & $\begin{array}{l}-0.254 \\
(0.208) \\
\end{array}$ & $\begin{array}{c}-0.469 * * * \\
(0.025)\end{array}$ & $60.63 \%$ \\
\hline
\end{tabular}




\begin{tabular}{|c|c|c|c|c|c|c|c|c|}
\hline & 3 Factor & $\begin{array}{c}0.116 \\
(0.635)\end{array}$ & $\begin{array}{c}0.837 * * * \\
(0.000)\end{array}$ & $\begin{array}{c}0.135 \\
(0.302)\end{array}$ & $\begin{array}{l}-0.197 \\
(0.115)\end{array}$ & - & $\begin{array}{l}- \\
-\end{array}$ & $59.38 \%$ \\
\hline \multirow{2}{*}{ Technology } & 5 Factor & $\begin{array}{c}0.932^{* *} \\
(0.015)\end{array}$ & $\begin{array}{c}0.777 * * * \\
(0.000)\end{array}$ & $\begin{array}{c}-0.515^{* * *} \\
(0.008)\end{array}$ & $\begin{array}{c}-1.139 * * * \\
(0.000)\end{array}$ & $\begin{array}{c}-1.955^{* * *} \\
(0.000)\end{array}$ & $\begin{array}{l}-0.478 \\
(0.112)\end{array}$ & $54.92 \%$ \\
\hline & 3 Factor & $\begin{array}{l}-0.086 \\
(0.824) \\
\end{array}$ & $\begin{array}{c}0.973^{* * *} \\
(0.000)\end{array}$ & $\begin{array}{c}-0.563^{* * *} \\
(0.007)\end{array}$ & $\begin{array}{c}-0.751 * * * \\
(0.000)\end{array}$ & $\begin{array}{l}- \\
- \\
-\end{array}$ & $\begin{array}{l}- \\
- \\
\end{array}$ & $44.04 \%$ \\
\hline \multirow{2}{*}{ Materials } & 5 Factor & $\begin{array}{l}0.035 \\
0.904\end{array}$ & $\begin{array}{c}0.825^{* * *} \\
(0.000)\end{array}$ & $\begin{array}{l}-0.009 \\
(0.950)\end{array}$ & $\begin{array}{c}0.385^{* *} \\
(0.047)\end{array}$ & $\begin{array}{c}0.451 * * \\
(0.046)\end{array}$ & $\begin{array}{c}-0.798^{* * *} \\
(0.001)\end{array}$ & $60.07 \%$ \\
\hline & 3 Factor & $\begin{array}{c}0.058 \\
(0.835)\end{array}$ & $\begin{array}{c}0.897 * * * \\
(0.000)\end{array}$ & $\begin{array}{c}0.125 \\
(0.403)\end{array}$ & $\begin{array}{l}-0.116 \\
(0.418)\end{array}$ & $\begin{array}{l}- \\
-\end{array}$ & $\begin{array}{l}- \\
-\end{array}$ & $57.01 \%$ \\
\hline \multirow{2}{*}{ Communication } & 5 Factor & $\begin{array}{l}0.483^{*} \\
(0.086)\end{array}$ & $\begin{array}{c}0.433^{* * *} \\
(0.000)\end{array}$ & $\begin{array}{c}-0.851 * * * \\
(0.000)\end{array}$ & $\begin{array}{c}-0.503 * * * \\
(0.007)\end{array}$ & $\begin{array}{c}-0.800 * * * \\
(0.000)\end{array}$ & $\begin{array}{c}-0.119 \\
0.592 \\
\end{array}$ & $44.99 \%$ \\
\hline & 3 Factor & $\begin{array}{c}0.058 \\
(0.835) \\
\end{array}$ & $\begin{array}{c}0.897 * * * \\
(0.000)\end{array}$ & $\begin{array}{c}0.125 \\
(0.403)\end{array}$ & $\begin{array}{l}-0.116 \\
(0.418)\end{array}$ & $\begin{array}{l}- \\
- \\
-\end{array}$ & $\begin{array}{l} \\
- \\
- \\
\end{array}$ & $40.64 \%$ \\
\hline \multirow{2}{*}{ Utilities } & 5 Factor & $\begin{array}{c}0.085 \\
(0.720)\end{array}$ & $\begin{array}{c}0.511 * * * \\
(0.000)\end{array}$ & $\begin{array}{c}-0.451 * * * \\
(0.000)\end{array}$ & $\begin{array}{c}0.361 * * \\
(0.022)\end{array}$ & $\begin{array}{c}0.399 * * \\
(0.029)\end{array}$ & $\begin{array}{l}-0.307 \\
(0.103)\end{array}$ & $48.79 \%$ \\
\hline & 3 Factor & $\begin{array}{c}0.169 \\
(0.447)\end{array}$ & $\begin{array}{c}0.529 * * * \\
(0.000)\end{array}$ & $\begin{array}{c}-0.388^{* * *} \\
(0.001)\end{array}$ & $\begin{array}{c}0.042 \\
(0.709)\end{array}$ & $\begin{array}{l}- \\
-\end{array}$ & $\begin{array}{l}- \\
-\end{array}$ & $46.95 \%$ \\
\hline
\end{tabular}

$(*),(* *),(* * *)$ denote significance at $10 \%, 5 \%$ and $1 \%$ level; $\mathrm{p}$-values are given in parentheses. 
Table 13: OLS regression estimates - European sectors.

\begin{tabular}{|c|c|c|c|c|c|c|c|c|}
\hline & Model & Alpha & $\begin{array}{c}\text { Market } \\
\text { Beta }\end{array}$ & $\begin{array}{l}\text { SMB } \\
\text { Beta }\end{array}$ & $\begin{array}{c}\text { HML } \\
\text { Beta }\end{array}$ & $\begin{array}{c}\text { RMW } \\
\text { Beta }\end{array}$ & $\begin{array}{l}\text { CMA } \\
\text { Beta }\end{array}$ & $\mathbf{R}^{2}$ \\
\hline \multirow{2}{*}{$\begin{array}{l}\text { Consumer } \\
\text { Discretionary }\end{array}$} & 5 Factor & $\begin{array}{l}-0.091 \\
(0.572)\end{array}$ & $\begin{array}{c}1.138^{* * *} \\
(0.000)\end{array}$ & $\begin{array}{c}0.054 \\
(0.338)\end{array}$ & $\begin{array}{c}0.180^{* * *} \\
(0.010)\end{array}$ & $\begin{array}{c}0.362^{* * * *} \\
(0.000)\end{array}$ & $\begin{array}{l}-0.092 \\
(0.346)\end{array}$ & $79.46 \%$ \\
\hline & 3 Factor & $\begin{array}{c}0.077 \\
(0.633)\end{array}$ & $\begin{array}{c}1.065^{* * *} \\
(0.000)\end{array}$ & $\begin{array}{l}-0.098^{*} \\
(0.055)\end{array}$ & $\begin{array}{c}0.248^{* * *} \\
(0.000)\end{array}$ & $\begin{array}{l} \\
- \\
\end{array}$ & $\begin{array}{l}- \\
-\end{array}$ & $77.41 \%$ \\
\hline \multirow{2}{*}{$\begin{array}{c}\text { Consumer } \\
\text { Staples }\end{array}$} & 5 Factor & $\begin{array}{l}-0.286^{*} \\
(0.064)\end{array}$ & \begin{tabular}{|c|}
$0.702^{* * *}$ \\
$(0.000)$ \\
\end{tabular} & $\begin{array}{c}-0.297 * * * \\
(0.000) \\
\end{array}$ & $\begin{array}{c}-0.160^{* *} \\
(0.016) \\
\end{array}$ & $\begin{array}{c}0.427 * * * \\
(0.000) \\
\end{array}$ & $\begin{array}{c}0.569 * * * \\
(0.000) \\
\end{array}$ & $58.52 \%$ \\
\hline & 3 Factor & $\begin{array}{c}0.059 \\
(0.722)\end{array}$ & $\begin{array}{c}0.525^{* * *} \\
(0.000)\end{array}$ & $\begin{array}{c}-0.390 * * * \\
(0.000)\end{array}$ & $\begin{array}{c}0.146^{* * *} \\
(0.007)\end{array}$ & $\begin{array}{l} \\
- \\
\end{array}$ & $\begin{array}{l}- \\
- \\
\end{array}$ & $47.11 \%$ \\
\hline \multirow{2}{*}{ Energy } & 5 Factor & $\begin{array}{l}-0.242 \\
(0.444)\end{array}$ & $\begin{array}{c}1.018^{* * *} \\
(0.000)\end{array}$ & $\begin{array}{c}0.079 \\
(0.477) \\
\end{array}$ & $\begin{array}{c}0.205 \\
(0.132)\end{array}$ & $\begin{array}{l}0.319^{* *} \\
(0.030)\end{array}$ & $\begin{array}{c}0.170 \\
(0.372)\end{array}$ & $44.29 \%$ \\
\hline & 3 Factor & $\begin{array}{l}-0.034 \\
(0.912)\end{array}$ & $\begin{array}{c}0.922^{* * *} \\
(0.000)\end{array}$ & $\begin{array}{l}-0.034 \\
(0.722)\end{array}$ & $\begin{array}{c}0.378^{* * *} \\
(0.000)\end{array}$ & $\begin{array}{l}- \\
-\end{array}$ & $\begin{array}{l}- \\
-\end{array}$ & $43.10 \%$ \\
\hline \multirow{2}{*}{ Financials } & 5 Factor & $\begin{array}{l}-0.236 \\
(0.139)\end{array}$ & $\begin{array}{c}1.132^{* * *} \\
(0.000)\end{array}$ & $\begin{array}{c}-0.334 * * * \\
(0.000)\end{array}$ & $\begin{array}{c}1.014^{* * * *} \\
(0.000)\end{array}$ & $\begin{array}{c}-0.233 * * * \\
(0.002)\end{array}$ & $\begin{array}{c}-0.225^{* *} \\
(0.020)\end{array}$ & $85.37 \%$ \\
\hline & 3 Factor & $\begin{array}{c}-0.415^{* * *} \\
(0.008)\end{array}$ & $\begin{array}{c}1.219^{* * *} \\
(0.000)\end{array}$ & $\begin{array}{c}-0.274 * * * \\
(0.000)\end{array}$ & $\begin{array}{c}0.785^{* * *} \\
(0.000)\end{array}$ & $\begin{array}{l}- \\
-\end{array}$ & $\begin{array}{l}- \\
-\end{array}$ & $84.63 \%$ \\
\hline \multirow{2}{*}{ Health Care } & 5 Factor & $\begin{array}{c}0.069 \\
(0.680) \\
\end{array}$ & $\begin{array}{c}0.794 * * * \\
(0.000) \\
\end{array}$ & $\begin{array}{c}-0.190 * * * \\
(0.001) \\
\end{array}$ & $\begin{array}{l}-0.110 \\
(0.126) \\
\end{array}$ & $\begin{array}{c}0.123 \\
(0.111)\end{array}$ & $\begin{array}{r}0.789 \\
(0.432) \\
\end{array}$ & $63.39 \%$ \\
\hline & 3 Factor & $\begin{array}{c}0.147 \\
(0.355)\end{array}$ & $\begin{array}{c}0.755^{* * * *} \\
(0.000)\end{array}$ & $\begin{array}{c}-0.229 * * * \\
(0.000)\end{array}$ & $\begin{array}{l}-0.080 \\
(0.119)\end{array}$ & $\begin{array}{l}- \\
-\end{array}$ & $\begin{array}{l}- \\
-\end{array}$ & $63.20 \%$ \\
\hline \multirow{2}{*}{ Industrials } & 5 Factor & $\begin{array}{l}-0.282^{*} \\
(0.056) \\
\end{array}$ & $\begin{array}{c}1.195^{* * *} \\
(0.000)\end{array}$ & $\begin{array}{l}-0.016 \\
(0.763)\end{array}$ & $\begin{array}{c}0.206^{* * *} \\
(0.001)\end{array}$ & $\begin{array}{c}0.302 \\
(0.000)\end{array}$ & $\begin{array}{c}0.140 \\
(0.114)\end{array}$ & $83.43 \%$ \\
\hline & 3 Factor & $\begin{array}{l}-0.094 \\
(0.520)\end{array}$ & $\begin{array}{c}1.106^{* * *} \\
(0.000)\end{array}$ & $\begin{array}{c}-0.116^{* *} \\
(0.012)\end{array}$ & $\begin{array}{c}0.344^{* * *} \\
(0.000)\end{array}$ & $\begin{array}{l}- \\
-\end{array}$ & $\begin{array}{l}- \\
-\end{array}$ & $82.05 \%$ \\
\hline
\end{tabular}




\begin{tabular}{|c|c|c|c|c|c|c|c|c|}
\hline \multirow{2}{*}{ Materials } & 5 Factor & $\begin{array}{l}-0.426 * \\
(0.060)\end{array}$ & $\begin{array}{c}1.276 \\
(0.000)\end{array}$ & $\begin{array}{c}0.256 \\
(0.747)\end{array}$ & $\begin{array}{l}0.178^{*} \\
(0.068)\end{array}$ & $\begin{array}{c}0.426^{* * *} \\
(0.000)\end{array}$ & $\begin{array}{l}0.255^{*} \\
(0.062)\end{array}$ & $70.09 \%$ \\
\hline & 3 Factor & $\begin{array}{l}-0.143 \\
(0.519)\end{array}$ & $\begin{array}{c}1.144 * * * \\
(0.000)\end{array}$ & $\begin{array}{l}-0.121^{*} \\
(0.086)\end{array}$ & $\begin{array}{c}0.406^{* * *} \\
(0.000)\end{array}$ & $\begin{array}{l}- \\
-\end{array}$ & $\begin{array}{l}- \\
-\end{array}$ & $67.87 \%$ \\
\hline \multirow{2}{*}{ Technology } & 5 Factor & $\begin{array}{c}0.111 \\
(0.530)\end{array}$ & $\begin{array}{c}1.171^{* * * *} \\
(0.000)\end{array}$ & $\begin{array}{c}-0.157^{* *} \\
(0.012)\end{array}$ & $\begin{array}{c}-0.454 * * * \\
(0.000)\end{array}$ & $\begin{array}{c}-0.284 \text { *** } \\
(0.001)\end{array}$ & $\begin{array}{c}-0.329 * * * \\
(0.002)\end{array}$ & $85.11 \%$ \\
\hline & 3 Factor & $\begin{array}{l}-0.120 \\
(0.493)\end{array}$ & $\begin{array}{c}1.279 * * * \\
(0.000)\end{array}$ & $\begin{array}{l}-0.062 \\
(0.260)\end{array}$ & $\begin{array}{c}-0.700^{* * *} \\
(0.000)\end{array}$ & $\begin{array}{l}- \\
-\end{array}$ & $\begin{array}{l}- \\
-\end{array}$ & $83.81 \%$ \\
\hline \multirow{2}{*}{ Utilities } & 5 Factor & $\begin{array}{l}-0.185 \\
(0.441)\end{array}$ & $\begin{array}{c}0.581^{* * *} \\
(0.000)\end{array}$ & $\begin{array}{c}-0.275^{* * *} \\
(0.001)\end{array}$ & $\begin{array}{l}-0.058 \\
(0.574)\end{array}$ & $\begin{array}{c}0.330^{* *} \\
(0.030)\end{array}$ & $\begin{array}{c}0.434 * * * \\
(0.003)\end{array}$ & $29.55 \%$ \\
\hline & 3 Factor & $\begin{array}{c}0.082 \\
(0.725)\end{array}$ & $\begin{array}{c}0.447^{* * *} \\
(0.000)\end{array}$ & $\begin{array}{c}-0.360^{* * *} \\
(0.000)\end{array}$ & $\begin{array}{c}0.164 * * \\
(0.032)\end{array}$ & $\begin{array}{l}- \\
-\end{array}$ & $\begin{array}{l}- \\
-\end{array}$ & $25.47 \%$ \\
\hline
\end{tabular}

$(*),(* *),(* * *)$ denote significance at $10 \%, 5 \%$ and $1 \%$ level; p-values are given in parentheses. 
We have also conducted unpaired t-test to check if the mean of Fama-French five factor sector alphas for both the U.S. and Europe are statistically different across different sectors. On the basis of the results (not presented here for economy of space) in the ten sectors under consideration in the Europe, 42 out of 55 pairs were found to be significantly different from each other, at 5\% level of significance whereas table 4 indicates that in the nine sectors under consideration in the U.S., 38 out of 45 pairs were found to be significantly different from each other, at $5 \%$ level of significance. To further assess whether the profitability (RMW) and investment (CMA) factors in the five-factor model are statistically significant, the redundant variable test has been performed ${ }^{1}$. According to the results of the Likelihood ratio test for the U.S. sectors, eight out of nine sector portfolios have statistically significant profitability coefficients (betas) except the Healthcare sector whereas only five out of nine sector portfolios have statistically significant investment coefficients (betas), at $10 \%$ significance level. However, for hypothesis three, eight out of nine sector portfolios have statistically significant both profitability and investment coefficients (betas) with the only exception of Healthcare sector. For the European sectors, seven out of ten sectors have statistically significant profitability coefficients (betas) whereas six out of ten sectors have statistically significant investment coefficients (betas), at $10 \%$ significance level. However, for

\footnotetext{
1 We used the Likelihood ratio test (LRT) for the redundant variable test. Likelihood ratio test (LRT) is a hypothesis test that assesses the "goodness of fit" between two nested statistical models on the basis of their likelihoods. "Nested models" refers to the fact that one model is a special case of another model. The primary assumption that goes into this diagnostic test is that three factor model is a part of five factor model, and further hypothesise that the coefficient of the variable under consideration is zero and therefore can be eliminated from the equation. The test statistics for the null hypothesis used on the redundant variables is standard F-statistic based on a sample from the F-distribution. (For economy of space the results are not presented here but are available upon request).
} 
hypothesis three, nine out of ten sector portfolios have statistically significant both profitability and investment coefficients (betas) with the only exception of Healthcare sector in Europe.

The model specification tests conducted to analyse the "goodness of fit" of RMW and CMA factors with higher statistically significant factors and higher r-square values of five factor model over the three factor model suggests that five-factor model is better suited to explain sector returns in both US and Europe. These results are in coherence with previous study conducted by Sarwar, Mateus, and Todorovic (2017) which also reported FF5 to be a better fit for the U.S. over FF3 model.

Tables 14 and 15 provide a summary of the results of long and short and only long trading strategies based on FF5 and FF3 factor models for the U.S. and Europe, respectively. The tables include annualised mean return, standard deviation, and Sharpe ratio for all the strategies. These tables can be used to draw comparisons among different strategies and between same strategies in different markets. Moreover, they suggest that both the FF5 and FF3 long only strategies were able to outperform the benchmark in Europe, but only long strategy based on FF3 was able to outperform the benchmark in the USA. However, interestingly the annualised returns of long only strategies by both FF3 and FF5 models do not show significant difference in the profitability, despite higher explanatory power and statistical significance of FF5 factor model in explaining sector returns. This finding is similar to Sarwar, Mateus, and Todorovic (2017).

We can also observe the failure of both FF5 and FF3 factor models alphas as indicators for sector rotation in case of long and short strategy. Long and short strategy based on FF5 and FF3 for both the U.S. and Europe show negative returns along with abnormally high standard deviation leading to negative Sharpe ratio. The volatility in long and short 
strategy returns in US has been around $60 \%$ and for Europe it has been around 93\%, which are substantially higher than the volatility of the returns of the benchmark for both the markets.

Table 14 reflects that the long only strategy based on FF3 and FF5 factor models for US sectors generated $1.3 \%$ and $1.4 \%$ higher returns respectively than the S\&P 500 along with slightly lower standard deviations in each case. Table 15 reflects that in Europe the long only strategy based on FF3 factor model generated $1.44 \%$ higher returns than the benchmark, however FF5 factor model-based strategy underperformed the benchmark by $0.02 \%$. Meanwhile both the long only strategies were successful in minimising the volatility of the returns considerably from $22.06 \%$ in the benchmark to just close to $14 \%$ in both the strategies. This led to relatively higher Sharpe ratio for both the strategies in comparison to the benchmark, almost double in case of FF3 long only strategy.

Table 14: The U.S. - Trading strategy performance

\begin{tabular}{|l|r|r|r|}
\hline Trading strategy & Mean return & Std. deviation & Sharpe ratio \\
\hline Long only based on Five factor alpha & $8.20 \%$ & $13.70 \%$ & 0.34 \\
\hline $\begin{array}{l}\text { Long \& short based on Five factor } \\
\text { alpha }\end{array}$ & $-7.60 \%$ & $61.10 \%$ & -0.18 \\
\hline Long only based on Three factor alpha & $8.10 \%$ & $13.80 \%$ & 0.33 \\
\hline $\begin{array}{l}\text { Long \& short based on Three factor } \\
\text { alpha }\end{array}$ & $-10.60 \%$ & $60.10 \%$ & -0.23 \\
\hline Buy \& Hold S\&P 500 & $6.80 \%$ & $14.10 \%$ & 0.23 \\
\hline
\end{tabular}

Table 15: Europe - Trading strategy performance

\begin{tabular}{|l|r|r|r|}
\hline Trading strategy & Mean return & Std. deviation & Sharpe ratio \\
\hline Long only based on Five factor alpha & $5.50 \%$ & $14.13 \%$ & 0.20 \\
\hline $\begin{array}{l}\text { Long \& short based on Five factor } \\
\text { alpha }\end{array}$ & $-26.45 \%$ & $94.80 \%$ & -0.31 \\
\hline Long only based on Three factor alpha & $6.96 \%$ & $14.03 \%$ & 0.31 \\
\hline $\begin{array}{l}\text { Long \& short based on Three factor } \\
\text { alpha }\end{array}$ & $-30.69 \%$ & $92.15 \%$ & -0.36 \\
\hline Buy \& Hold S\&P 500 & $5.52 \%$ & $22.06 \%$ & 0.13 \\
\hline
\end{tabular}


The effective results of the strategy based on FF3 and FF5 indicators over the buy and hold strategy of benchmark portfolios for both the U.S. and Europe can be observed in Figures 5 and 6 . These figures represent the performance of all the strategies outlined in tables 14 and 15 over the time period under consideration and also displays the cumulative growth in the returns over time in comparison to the benchmark portfolios. As can be observed from both the figures, sector rotation strategies based on FF3 and FF5 alphas have managed to consistently outperform the market, which is in line with the findings by Sarwar, Mateus, and Todorovic (2017).

\section{Figure 5: The U.S. - Sector Rotation Strategies Performances}

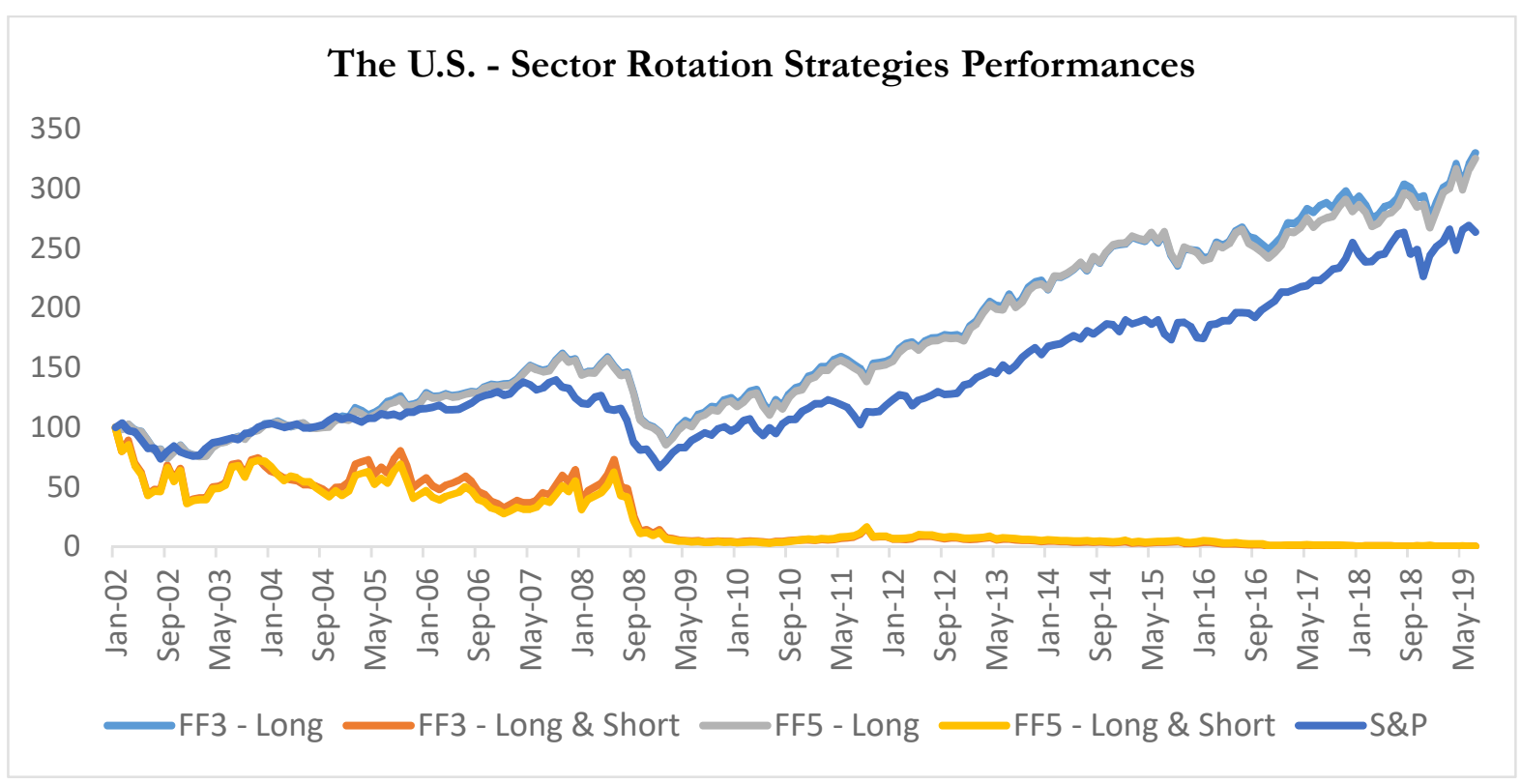




\section{Figure 6: Europe - Sector Rotation Strategies Performance}

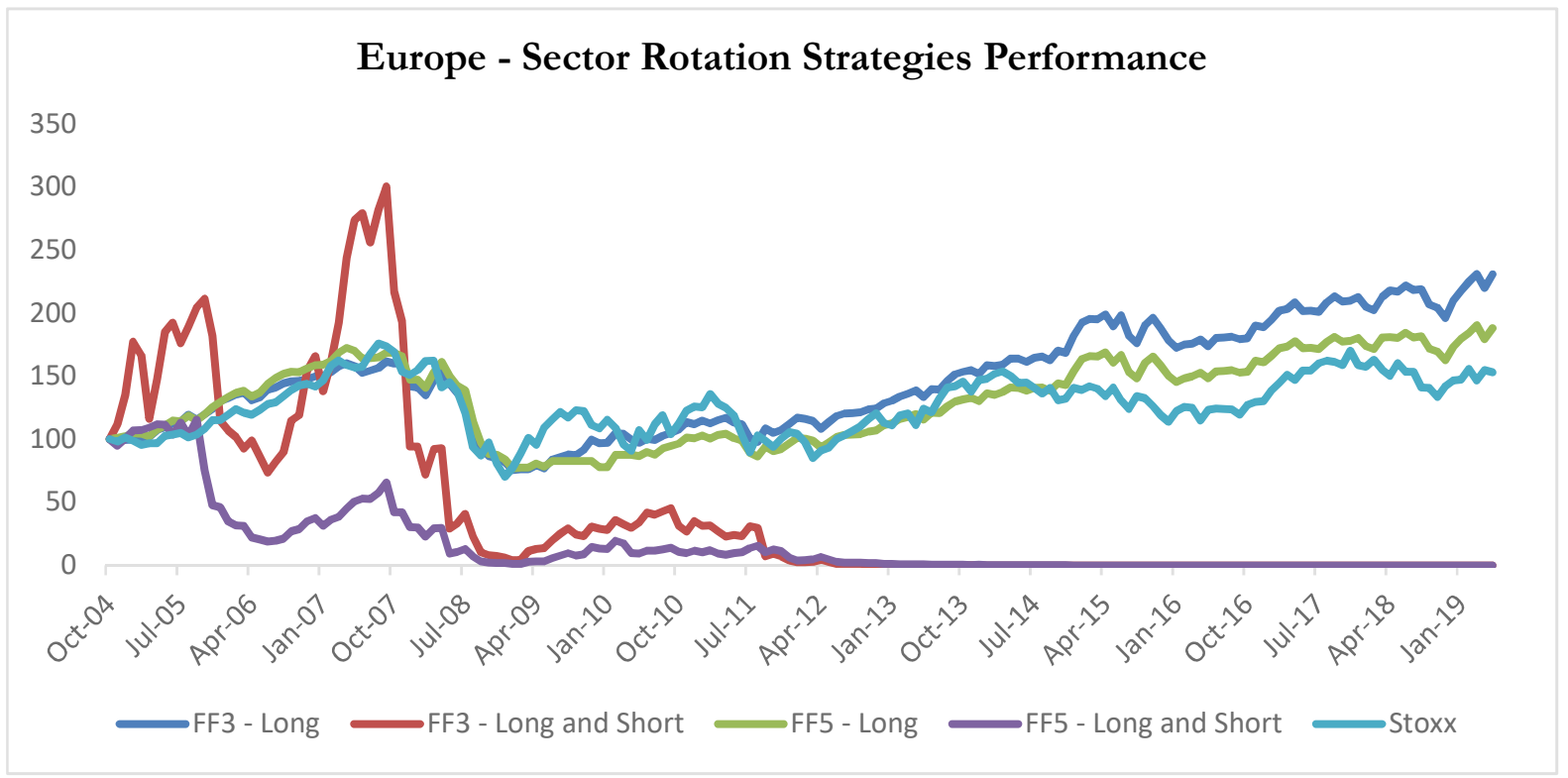

\section{Conclusions}

As mentioned previously, the purpose of this paper is to determine the performance of sector rotation strategies under a range of different factors to determine its viability and practicality. Three indicators were used to understand their respective impact within both the U.S. and the European market in an attempt to establish consistent results. It would be unrealistic to express an opinion with strong conviction that sector rotation strategies come without any limitations and will generate abnormal returns every time. However, there are indications implying that under certain circumstances, sector rotation strategy holds its ground and can be considered a viable investment approach.

The economic indicator, which in this case is the interest rate, shows as per the results of the analysis that within the European market, sector rotation strategies tend to produce returns above the average benchmark, both during contractionary and expansionary monetary policy regimes. A similar impact can be seen for the technical indicator (momentum), where the results show the presence of higher returns, whilst in the case of 
the performance indicator, excessive returns within both the US and European markets are observed.

Additional factors such as the volatility has also been used for robustness. More specifically, the significance of the technical indicator with regards to the US market can be considered statistically negligible. In this context, excessive returns generated within the European market under the performance indicator may actually be only due to the reduction in volatility rather than an increase in the real returns of the strategy.

This paper examined multiple macroeconomic factors ranging from as simple as changes in interest rates to consumer sentiment in an attempt to establish whether there exists a "universal" switching indicator that can perhaps predict the right timing to switch between sectors. However, in most of the cases the results for both the economies have turned out to be significantly different for almost all the switching indicators. This perhaps leads one to believe that there might not be a true "universal" indicator that predicts the right timing to switch between sectors. It does, however, make one think that there may be a combination of several factors that potentially indicate the right timing to switch. In view of the above, we urge future researchers to build upon our work and investigate this prospect.

The main conclusion, and in turn the potential questions this paper draws is that under certain circumstances and specific factors, the potential to earn excessive return using sector rotation strategies may in fact be quite plausible, thus proving its reliability. However, it is essential to further understand what these potential factors may be. Further in-depth analysis within different markets, various individual factors, and other potential indicators is required to truly understand the effectiveness of sector rotation strategies. If anything, upon completion, this paper may enable the researchers to appreciate the 
complexity behind appreciating sector rotation strategies and develop further questions towards the direction of improving their practical reliability.

Future directions as to how to improve or build upon the existing work as well as find ways to circumvent the existing challenges may be considered in the following context. Firstly, the lack of availability of data of ETFs for both the U.S. and Europe presents a challenge as the data is only available post 1999 , and during most of the time after that till today both the U.S. and European market have faced major economic downturns and have mostly been in either recession or recovering phase up until recently. This could lead to the data being biased and influence the empirical results. Secondly, the lack of sector ETFs for emerging countries restricted the study to only developed economies. The study of sector rotation strategy via sector ETFs in emerging countries would have presented a more holistic idea about the effectiveness of the sector rotation strategy. Lastly, incorporating transaction costs in a future research study might provide further insights, hence, exposing additional aspects of sectoral rotation when the allocation process of transaction costs is considered. 


\section{References}

Aharoni, G., Grundy, B. and Zeng, Q. 2013. Stock returns and the Miller Modigliani valuation formula: Revisiting the Fama French analysis, Journal of Financial Economics 110(2): 347357.

Baca, S., Garbe, B., and Weiss, A. 2000. The rise of sector effects in major equity markets. Financial Analysts Journal 56 (5): 34-40. http://DOI: 10.2469/faj.v56.n5.2388.

Beller, K., Kling, J. and Levinson. M. 1998. Are industry stock returns predictable? Financial Analysts Journal 54 (5): 42-57.

Bernanke, B. and Kuttner. K. 2005. What explains the stock market's reaction to Federal Reserve Policy?. Journal of Finance 60: 1221-1257.

Carhart, M. 1997. On persistence in mutual fund performance. Journal of Finance 52: 57-82.

Cavaglia, S, and Moroz, V. 2003. Cross-industry, cross-country allocation. Financial Analysts Journal 58 (6): 78-97. http:// DOI:10.2469/faj.v58.n6.2488.

Chan, L.K.C. and Jegadeesh, N. and Lakonishok, J. 1995. Momentum strategies. NBER Working Paper No. w5375.

Chen, L., Novy-Marx, R. and Zhang, L. 2011. An alternative three-factor model. Working Paper. 10.2139/ssrn.1418117.

Chordia, T., and Shivakumar, L. 2002. Momentum, business cycle, and time-varying expected returns. Journal of Finance 57: 985-1019.

Conover, M., Jensen, G., Johnson, R. and Mercer. J. 2005. Is Fed Policy still relevant for investors?. Financial Analysts Journal 61(1): 70-79.

Doeswijk, R. and van Vliet, P. 2010. Global tactical sector allocation: A quantitative approach. https://ssrn.com/abstract=1742422 or http://dx.doi.org/10.2139/ssrn.1742422. Accessed 16 September 2019. 
De Bondt, W. and Thaler, R. 1985. Does the stock market overreact?. Journal of Finance 40: 793-805.

Dellva, W. L., DeMaskey, A. L. and Smith, C. 2001. Selectivity and market timing performance of fidelity sector mutual funds. The Financial Review 36(1): 39-54.

Dedola, L. and Lippi, F. 2005. The monetary transmission mechanism: Evidence from the industries of five OECD countries. European Economic Review 49(6): 1543-1569.

Dou, P. Y., Gallagher, D. R., Schneider, D. and Walter, T. S. 2014. Cross-region and cross sector asset allocation with regimes. Accounting and Finance 54: 809-846.

Ehrmann, M. and Fratzscher, M. 2004. Taking stock: Monetary policy transmission to equity markets. ECB Working Paper No. 354.

Fama, E. and French, K. 1993. Common risk factors in the returns on stocks and bonds. Journal of Financial Economics 33: 3-56.

Fama, E. and French, K. 2015. A five-factor ssset pricing model. Journal of Financial Economics 116: 1-22.

Grauer, R. R., Hakansson, N. H. and Shen, F. C. 1990. Industry rotation in the US stock market: 1934-1986 returns on passive, semi-passive, and active Strategies. Journal of Banking and Finance 14 (2): 513-538.

Grinblatt, M. and Titman, S. 1989. Mutual fund performance: An analysis of quarterly portfolio holdings. The Journal of Business 62(3): 393-416.

Grundy, B. D., and Spencer M. 2001. Understanding the nature of the risks and the source of the rewards to momentum investing. Review of Financial Studies 14: 29-78.

Hayo, B. and Uhlenbrock, B. 1999. Industry effects of monetary policy in Germany. ZEI Working Paper, No. B 14-1999, Rheinische Friedrich-Wilhelms-Universität Bonn, Zentrum für Europäische Integrationsforschung (ZEI), Bonn. 
Jacobsen, B, Stangl, J, and Visaltanachoti, N. 2009. Sector rotation over the business cycle. Working Paper, Massey University, Department of Finance and Economics.

Jacquier, E., Kane, A. and Marcus, A. 2003. Geometric or arithmetic mean: A reconsideration. Financial Analysts Journal. 59: 46-53.

Jensen, G. and Johnson. R. 1995. Discount rate changes and security returns in the U.S., 19621991. Journal of Banking and Finance 19: 79-95.

Jensen M. and Bennington, G. 1970. Random walks and technical theories: Some additional evidence. Journal of Finance 25(2): 469-82.

Jegadeesh, N. and Titman, S. 1993. Returns to buying winners and selling losers: implications for stock market efficiency. Journal of Finance 48: 65-91.

Jegadeesh N. 1990. Evidence of predictable behavior of security returns. Journal of Finance 45: 881-898.

Kacperczyk, M., Sialm, C. and Zheng, L. U. 2005. On the industry concentration of actively managed equity mutual funds. Journal of Finance 60(4): 1983-2012.

Kouzmenko, R. and Nagy, Z. 2009. Sector performance across business cycles. MSCI Research Bulletin.

Lehmann B. N. 1990. Fads, martingales and market efficiency. Quarterly Journal of Economics 105: 1-28.

Luk, P. 2012. Is there value in Asia ex-Japan sector rotation strategies? Index Research and Design 
https://us.spindices.com/documents/research/research-is-there-value-in-asia-ex-japan-sectorrotation-strategies-201210.pdf. Accessed 15 October 2019.

Moskowitz, T. and Grinblatt, M. 1999. Do industries explain momentum?. Journal of Finance 54: $1249-1290$.

O’Neal, E. 2000. Industry momentum and sector mutual funds. Financial Analysts Journal 56(4): 37-49.

Parvez, A., Lockwood, L. and Sudhir N. 2002. Multi-style rotation strategies. Journal of Portfolio Management 28: 17-29.

Peterson, P. and Fabozzi, F. 2009. Finance: capital markets, financial management, and investment management. John Wiley and Sons, Inc.

Rapach, D., Strauss, J., Tun, J. and Zhou, G. 2015. Industry interdependence and cross-industry return predictability. Working paper, Research collection, Lee Kong Chian School of Business https://ink.library.smu.edu.sg/lkcsb_research/4515. Accessed 20 October 2019.

Robert. L. 1967. Relative strength as a criterion for investment selection. The Journal of Finance 22: 595-610. https://doi:10.1111/j.1540-6261.1967.tb00295.x

Sarwar, G., Mateus, C. and Todorovic, N. 2017. US sector rotation with five-factor FamaFrench alphas. https://ssrn.com/abstract=2987819 or http://dx.doi.org/10.2139/ssrn.2987819. Accessed 25 October 2019.

Schnabl, G. and Stratmann T. 2019. Fed policy vs. ECB policy: A comparison. https://mises.org/wire/fed-policy-vs-ecb-policy-comparison. Accessed 27 December 2019. Scowcraft, A. and Sefton, J. 2005. Understanding momentum. Financial Analyst Journal 61 (2): 64-82.

Siegel, F. and Hoban, J. 1991. Measuring risk aversion: Allocation, leverage, and accumulation. The Journal of Financial Research 14(1): 27-35. 
Sorensen, E. H., and Burke. T. 1986. Portfolio returns from active industry group rotation. Financial Analysts Journal 42(5): 43-50.

Spiess, D. K. and Affleck-Graves, J. 1995. Underperformance in long-run stock returns following seasoned equity offerings. Journal of Financial Economics 38(3): 243-267. Swinkels, L. and Tjong-A-Tjoe, L. 2006. Can mutual funds time investment styles?. https://ssrn.com/abstract=1003127. Accessed 26 September 2019. Walkshäusl, C. and Lobe, S. 2014. The alternative Three-Factor Model: An alternative beyond US markets?. European Financial Management 20(1): 33-70. 


\section{APPENDIX}

Table 1. Pictorial representation of sector rotation strategy

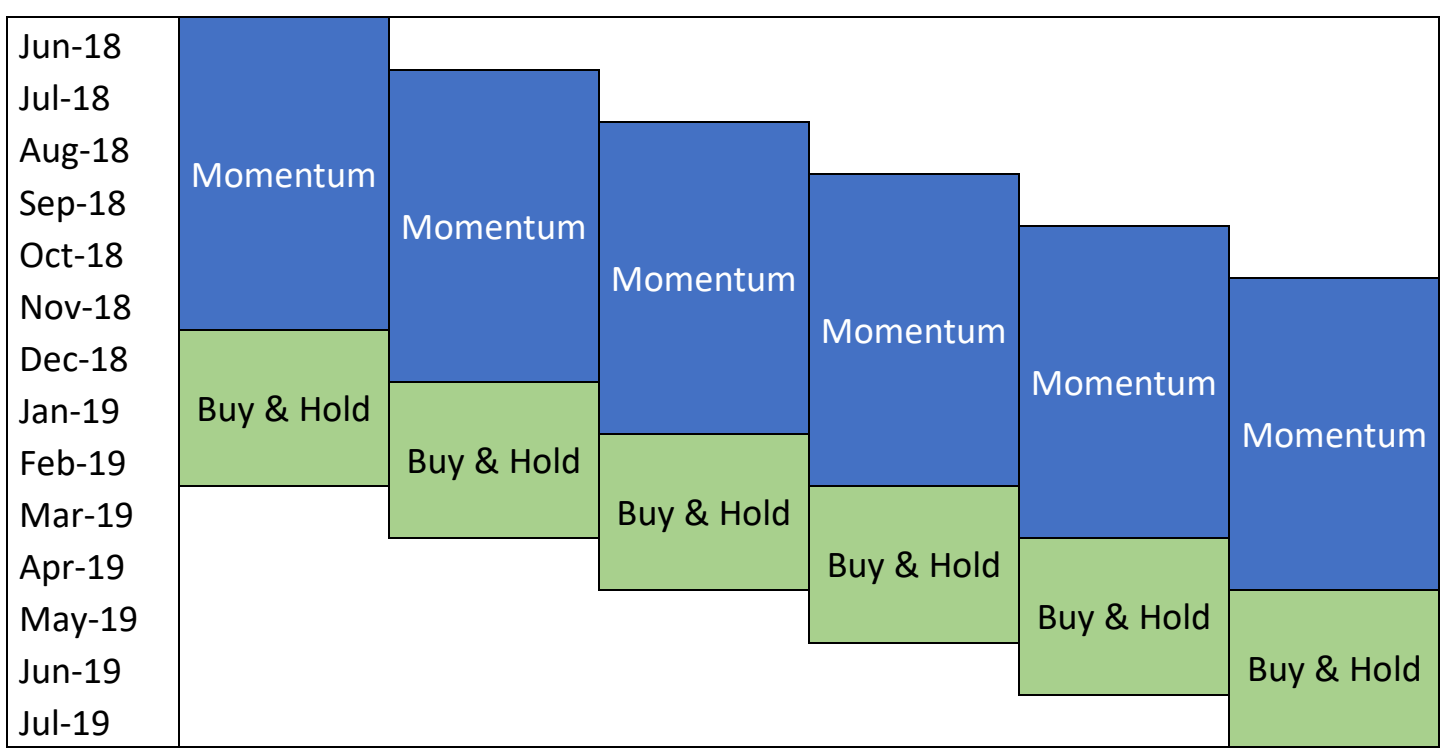

Table 2. The U.S. sector rotation portfolio vs benchmark (1999 to 2019) - GDP

\begin{tabular}{|l|c|c|c|}
\hline & Mean (Annual Return) & Std Dev (Yearly) & Return to risk \\
\hline Portfolio & $7.05 \%$ & $71.05 \%$ & 0.12 \\
\hline Benchmark & $7.04 \%$ & $14.70 \%$ & 0.48 \\
\hline Excess return & $0.01 \%$ & & \\
\hline
\end{tabular}

Table 3. European sector rotation portfolio vs benchmark (1999 to 2019) - GDP

\begin{tabular}{|l|c|c|c|}
\hline & Mean (Annual Return) & Std Dev (Yearly) & Return to risk \\
\hline Portfolio & $4.60 \%$ & $64.19 \%$ & 0.09 \\
\hline Benchmark & $8.53 \%$ & $21.76 \%$ & 0.39 \\
\hline Excess return & $-3.93 \%$ & & \\
\hline
\end{tabular}


Figure 1. Sector rotation performance based on momentum in the U.S. - One-month momentum

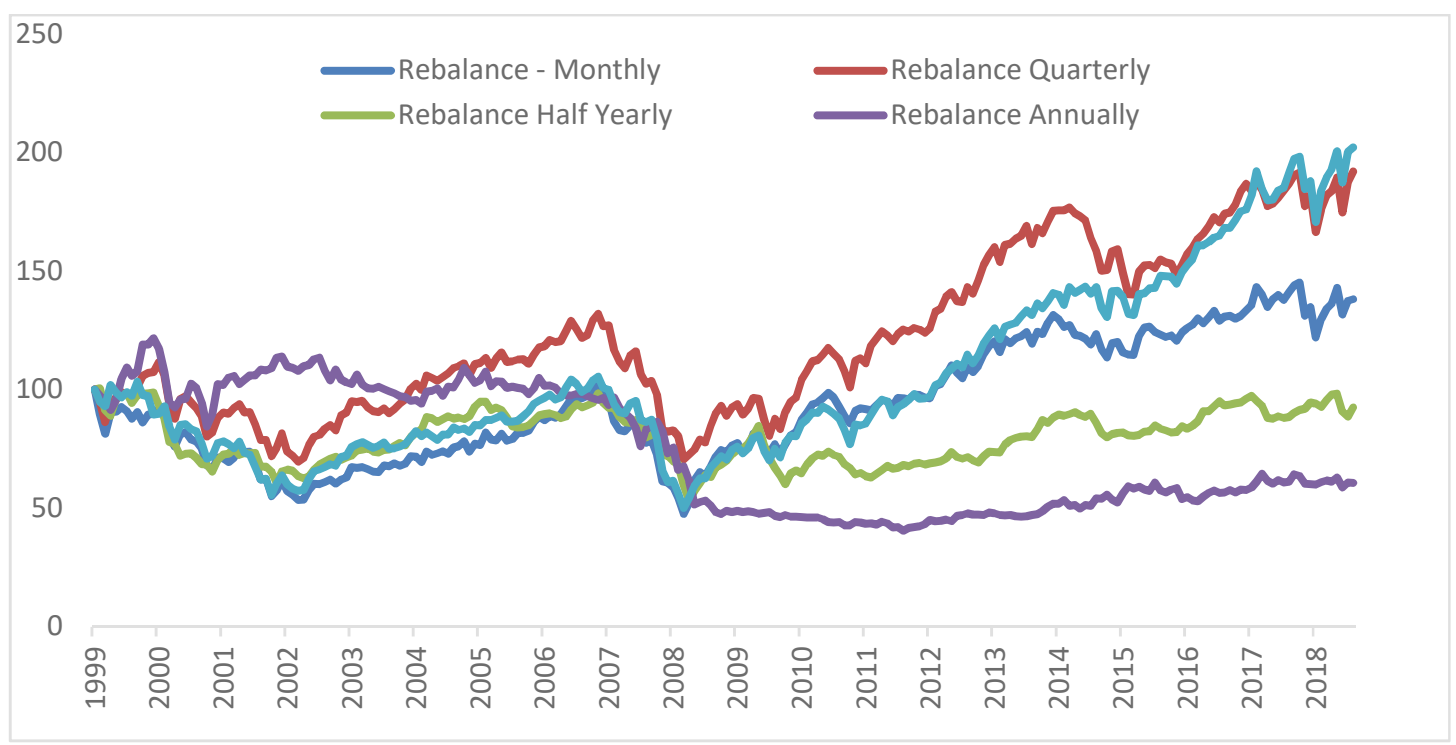

Figure 2. Sector rotation performance based on momentum in the U.S. - 3-month momentum.

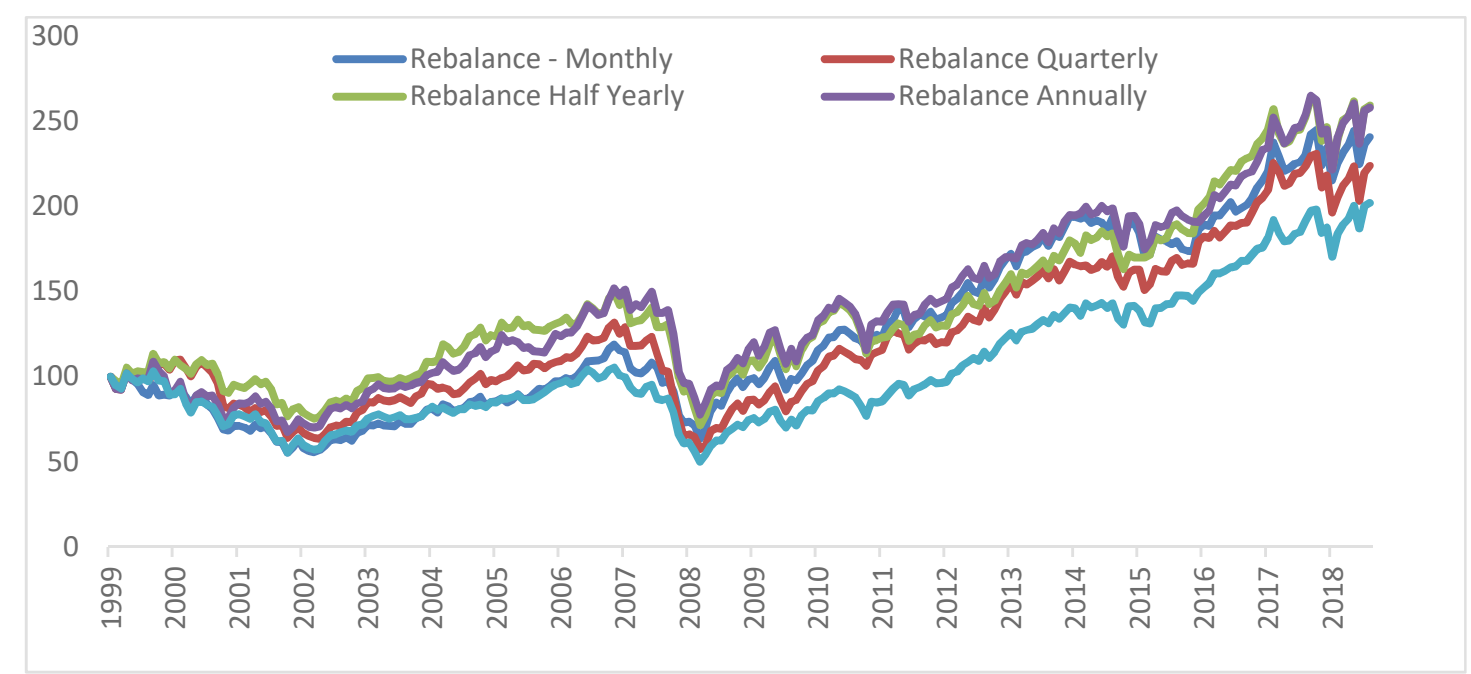


Figure 3. Sector rotation performance based on momentum in the U.S. - 6-month momentum

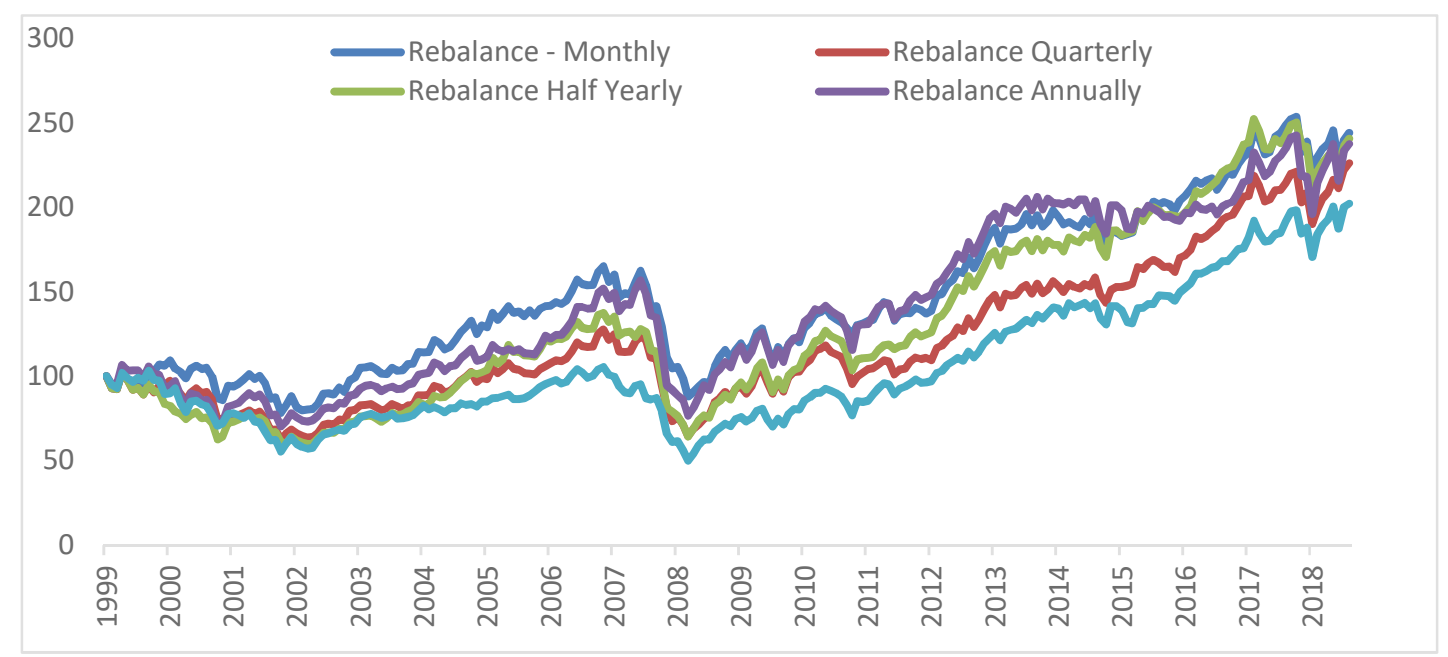

Figure 4. Sector rotation performance based on momentum in the U.S. - 12-month momentum

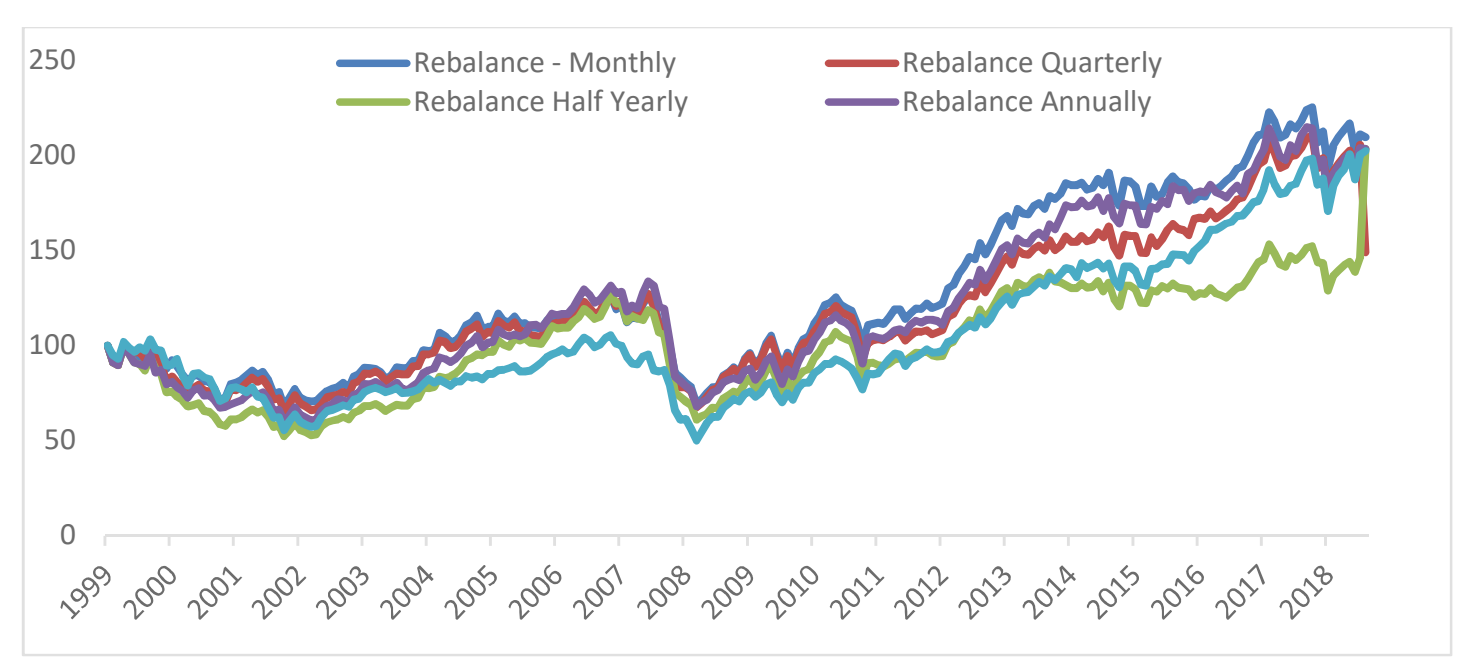


Figure 5. Sector rotation performance based on momentum in Europe - 1-month momentum

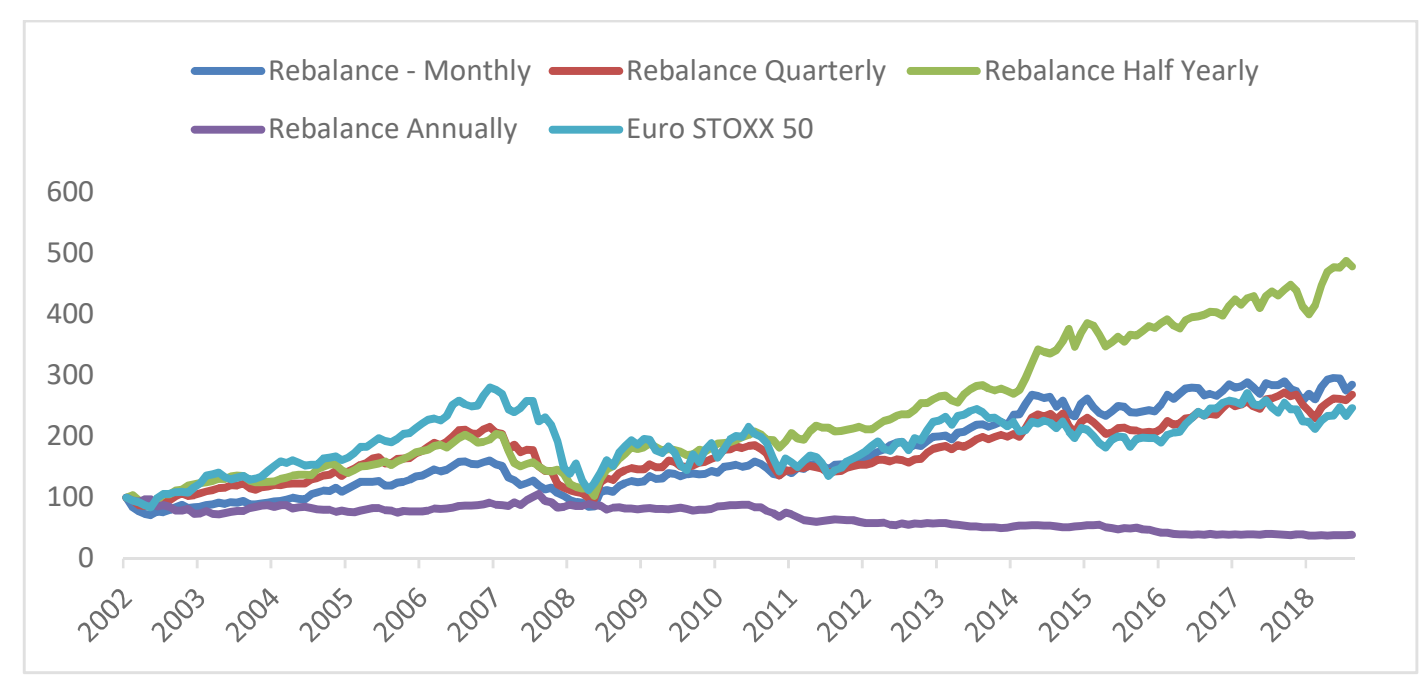

Figure 6. Sector rotation performance based on momentum in Europe: - 3-month momentum.

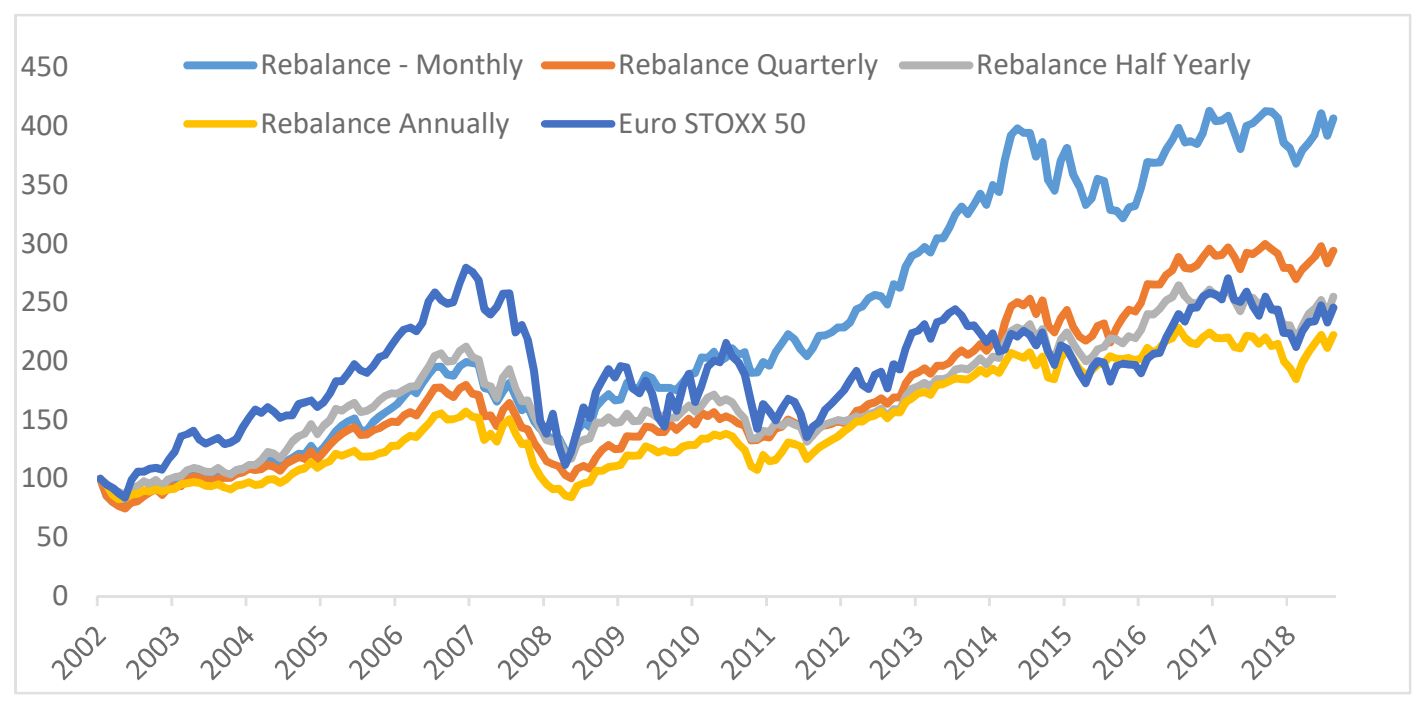


Figure 7. Sector rotation performance based on momentum in Europe - 6-month momentum

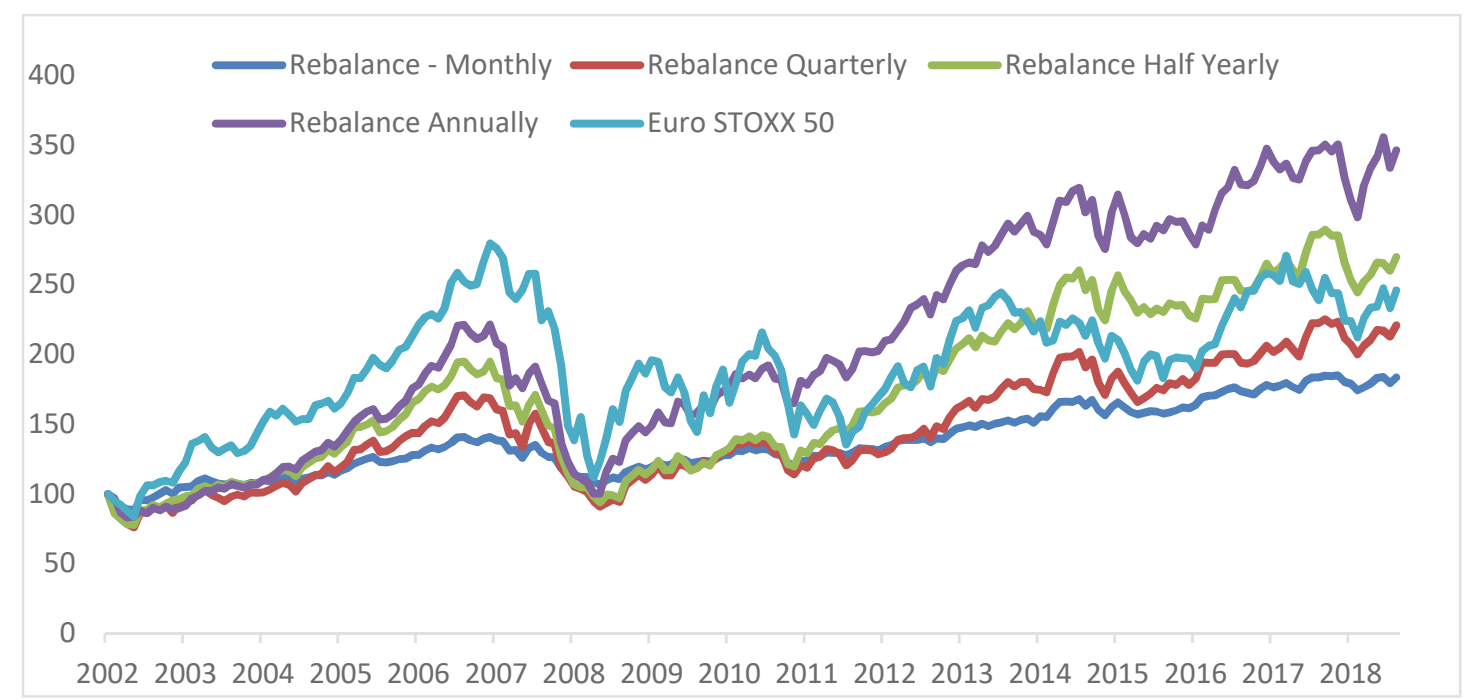

Figure 8. Sector rotation performance based on momentum in Europe - 12-month momentum

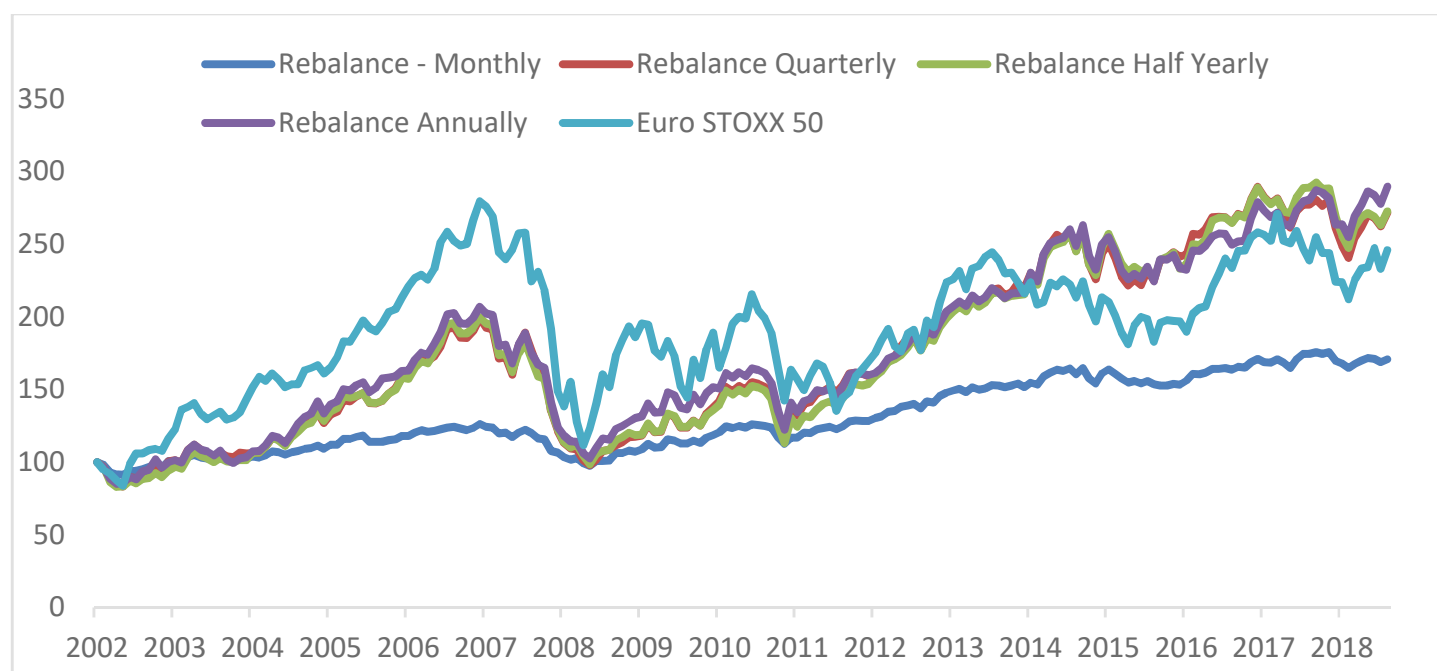

